\title{
Differential Mechanisms of Transmission at Three Types of Mossy Fiber Synapse
}

\author{
Katalin Toth, Gregory Suares, J. Josh Lawrence, Emily Philips-Tansey, and Chris J. McBain \\ Laboratory of Cellular and Molecular Neurophysiology, National Institute of Child Health and Human Development, National \\ Institutes of Health, Bethesda, Maryland 20892-4495
}

\begin{abstract}
The axons of the dentate gyrus granule cells, the so-called mossy fibers, innervate their inhibitory interneuron and pyramidal neuron targets via both anatomically and functionally specialized synapses. Mossy fiber synapses onto inhibitory interneurons were comprised of either calcium-permeable (CP) or calciumimpermeable $(\mathrm{Cl})$ AMPA receptors, whereas only calciumimpermeable AMPA receptors existed at CA3 principal neuron synapses. In response to brief trains of high-frequency stimuli (20 $\mathrm{Hz}$ ), pyramidal neuron synapses invariably demonstrated shortterm facilitation, whereas interneuron EPSCs demonstrated either short-term facilitation or depression. Facilitation at all $\mathrm{Cl}$ AMPA synapses was voltage independent, whereas EPSCs at CP AMPA synapses showed greater facilitation at -20 than at $-80 \mathrm{mV}$, consistent with a role for the postsynaptic unblock of polyamines. At pyramidal cell synapses, mossy fiber EPSCs possessed marked frequency-dependent facilitation (commencing at stimulation frequencies $>0.1 \mathrm{~Hz}$ ), whereas EPSCs at either type of interneuron synapse showed only moderate frequency-
\end{abstract}

Dentate gyrus granule cells transmit information to the CA3 hippocampus via their so-called "mossy fiber" axons, which comprise the second synapse of the classic trisynaptic hippocampal circuit (for review, see Henze et al., 2000). A single granule cell axon forms a limited divergent pathway, making synaptic contact with only a few dozen hilar mossy cells and CA3 pyramidal neurons (Amaral et al., 1990). However, Ramon y Cajal (1911) noted a unique property of mossy fiber axons: unlike any other cortical principal cell, granule cell axons have more than one terminal type. These include large mossy fiber boutons, small en passant terminals, and filopodial extensions of the mossy fiber boutons (Blackstad and Kjaerheim, 1961; Amaral, 1979; Claiborne et al., 1986; Chicurel and Harris, 1992). In a more recent study Acsady et al. (1998) demonstrated that mossy fibers only innervate pyramidal cells via the large complex mossy boutons, whereas either small en passant or filopodial terminals preferentially target stratum lucidum inhibitory interneurons. This observation provided the first clue that the mossy fiber system may be functionally specialized depending on the nature of the postsynaptic target cell. More important, the observation that mossy inputs onto inhibitory cells outnumbered those onto principal cells by 10 -fold suggested that GABAergic cells are the major postsynaptic targets of granule cells.

Direct evidence of functional specialization of these distinct mossy fiber synaptic types came from two studies (Maccaferri et al., 1998; Toth and McBain, 1998; for review, see McBain et al., 1999; Toth and McBain, 2000). Mossy fiber transmission onto

\footnotetext{
Received July 24, 2000; revised Aug. 28, 2000; accepted Aug. 29, 2000.

This work was support by a National Institutes of Health intramural research award. We thank Orinthial McIntyre for his help with the post hoc processing of cells and Dr. Vittorio Gallo for his comments on this manuscript.

K.T. and G.S. contributed equally to this work.

Correspondence should be addressed to Dr. Chris J. McBain, Room 5A72, Building 49, Convent Drive, Bethesda, MD 20892-4495. E-mail: chrismcb@codon.nih.gov. Copyright (C) 2000 Society for Neuroscience $0270-6474 / 00 / 208279-11 \$ 15.00 / 0$
}

dependent facilitation or underwent depression. Presynaptic metabotropic glutamate receptors (mGluRs) decreased transmission at all three synapse types in a frequency-dependent manner. However, after block of presynaptic mGluRs, transmission at interneuron synapses still did not match the dynamic range of EPSCs at pyramidal neuron synapses. High-frequency stimulation of mossy fibers induced long-term potentiation (LTP), long-term depression (LTD), or no change at pyramidal neuron synapses, interneuron CP AMPA synapses, and CI AMPA synapses, respectively. Induction of LTP or LTD altered the shortterm plasticity of transmission onto both pyramidal cells and interneuron CP AMPA synapses by a mechanism consistent with changes in release probability. These data reveal differential mechanisms of transmission at three classes of mossy fiber synapse made onto distinct targets.

Key words: interneuron; GABAergic; Ca-permeable; AMPA receptor; LTP; mGluR stratum lucidum inhibitory interneurons was made via synapses comprised of either calcium-permeable (CP) or calciumimpermeable (CI) AMPA receptors (Toth and McBain, 1998). In contrast, it has been assumed, although not formally tested, that mossy fiber synapses on CA3 pyramidal cells contain only CI AMPA receptors because principal cells of the hippocampus express high levels of the GluR2 subunit (Jonas and Burnashev, 1995; Spruston et al., 1995). In addition, an NMDA-independent form of long-term potentiation (LTP) common to mossy fiber synapses on principal cells (Zalutsky and Nicoll, 1990; Yeckel et al., 1999) was absent at synapses onto inhibitory interneurons, whereas a population of synapses even underwent long-term depression (LTD) in response to tetanic stimulation (Maccaferri et al., 1998).

Despite these previous studies, little information exists about basic mechanisms and regulation of mossy fiber transmission at interneuron synapses, compared with principal cell synapses (for review, see Henze et al., 2000). The recent demonstrations of target-specific expression of presynaptic and postsynaptic mechanisms of synaptic transmission between various cortical and hippocampal neurons (Maccaferri et al., 1998; Markram et al., 1998; Reyes et al., 1998; Scanziani et al., 1998; Toth and McBain, 1998; Reyes and Sakmann, 1999) prompted us to investigate synaptic transmission between the dentate gyrus and CA3 via these three synapse types. Specifically, we wanted to determine whether factors influencing presynaptic and postsynaptic mechanisms of transmission [i.e., short- and long-term plasticity, frequency-dependent facilitation, and metabotropic glutamate receptor (mGluR) regulation] were common at mossy fiber synapses onto both principal cells and inhibitory neurons.

\section{MATERIALS AND METHODS}

Hippocampal slice preparation. Transverse hippocampal slices $(300 \mu \mathrm{m})$ were obtained from 16- to 25-d-old Sprague Dawley rats as described previously (Maccaferri and McBain, 1995). This age range of animals was chosen because mossy fiber expansions are close to their mature form (Amaral and Dent, 1981). Rats were deeply anesthetized with isoflurane, 
and the brain was dissected out in ice-cold saline solution that contained (in mM): $130 \mathrm{NaCl}, 24 \mathrm{NaHCO}_{3}, 3.5 \mathrm{KCl}, 1.25 \mathrm{NaH}_{2} \mathrm{PO}_{4}, 1.0 \mathrm{CaCl}_{2}, 5.0$ $\mathrm{MgCl}_{2}$, and 10 glucose, saturated with $95 \% \mathrm{O}_{2}$ and $5 \% \mathrm{CO}_{2}, \mathrm{pH} 7.4$. All animal procedures conformed to the National Institutes of Health animal welfare guidelines.

Electrophysiological methods. All recordings were performed in an extracellular medium of the following composition (in $\mathrm{mM}$ ): $130 \mathrm{NaCl}, 24$ $\mathrm{NaHCO}_{3}, 3.5 \mathrm{KCl}, 1.25 \mathrm{NaHPO}_{4}, 2.5 \mathrm{CaCl}_{2}, 1.5 \mathrm{MgCl}_{2}$, and 10 glucose, saturated with $95 \% \mathrm{O}_{2}$ and $5 \% \mathrm{CO}_{2}, \mathrm{pH} 7.4$. Whole-cell patch-clamp recordings were made from $\mathrm{CA} 3$ pyramidal cells and interneurons located within the stratum lucidum of CA3 by the use of either a modified Axopatch 200A or Axopatch 1D amplifier (Axon Instruments, Foster City, CA) in voltage-clamp mode. All cells were initially identified on the basis of somata shape and position within the CA3 subfield using infrared video microscopy and differential interference contrast optics. Recordings were made at room temperature $\left(\sim 24^{\circ} \mathrm{C}\right)$ at a holding potential of $-60 \mathrm{mV}$, unless otherwise indicated. Recording electrodes were filled with the following (in $\mathrm{mM}$ ): 100 Cs-gluconate, $0.6 \mathrm{EGTA}, 5 \mathrm{MgCl}_{2}, 8 \mathrm{NaCl}, 2 \mathrm{ATP}_{2} \mathrm{Na}, 0.3 \mathrm{GTPNa}$, 40 HEPES, 0.1 spermine, and $1 \mathrm{~N}$-(2,6-dimethylphenyl carbamoylmethyl)triethylammonium bromide, $\mathrm{pH} 7.2-7.3$. Biocytin $(0.2 \%)$ was routinely added to the recording electrode solution to allow post hoc morphological processing of the recorded cells (for methods, see Toth and McBain, 1998). In recordings in which the cell morphology was not subsequently recovered or positively identified as either an inhibitory interneuron or pyramidal cell where appropriate, cells were eliminated from the data set. Series resistance was rigorously monitored by the delivery of $-5 \mathrm{mV}$ voltage steps after each evoked EPSC. Experiments were discontinued if the series resistance increased by $>10 \%$. Series resistances typically ranged from 6 to $25 \mathrm{M} \Omega$ and were not compensated.

Synaptic responses were evoked by low-intensity stimulation (100-160 $\mu$ sec duration; $17-45 \mu \mathrm{A}$ intensity) of granule cells in the dentate gyrus or the stratum lucidum of the hippocampal CA3 region via a constant-current isolation unit (A360; World Precision Instrument, Sarasota, FL) connected to a patch electrode that was filled with oxygenated extracellular solution. Bicuculline methobromide $(1-5 \mu \mathrm{M})$ or picrotoxinin $(100 \mu \mathrm{M})$ was routinely added to the extracellular medium to reduce inhibition. Synaptic responses were included in the analysis if the rise times and decay time constants were monotonic and possessed no obvious multiple EPSCs or polysynaptic waveforms under normal $\left[\mathrm{Ca}^{2+}\right]$ conditions. The stimulus intensity was set to the lowest value that reliably evoked a single EPSC waveform. EPSC latencies, rise times, and decay time constants were obtained from 10 to 30 individual traces within a given experiment and then averaged to obtain a mean value. Latencies were determined as the time interval between the center of the stimulus artifact and the beginning of the EPSC (Jonas et al., 1993). The onset of the EPSC was determined by extrapolating the $10-90 \%$ linear regression fit of the rise time back to the baseline current. Traces (10-30) in which stimuli evoked no synaptic event (i.e., failures) were averaged together and subtracted from all synaptic records to obtain stimulus artifact-free records of EPSCs for accurate amplitude measurement. EPSC amplitudes were determined from the response during a $1-1.5 \mathrm{msec}$ window around the peak of the waveform. In all figures, EPSCs were averaged only after the effect of the drug reached steady state. Data are presented as means \pm SEM. Unpaired and paired Student's $t$ tests were used for statistical analysis as appropriate; $p$ values are reported throughout the text.

Drugs. All compounds were obtained from Sigma-Aldrich (St. Louis, MO) unless stated otherwise. Philanthotoxin-433 tris-trifluoracetate (PhTx) was obtained from Research Biochemicals (Natick, MA). $\left(2 S, 2^{\prime} R, 3^{\prime} R\right)-2-\left(2^{\prime}, 3^{\prime}\right.$-dicarboxycyclopropyl)glycine (DCG-IV) was obtained from Tocris Cookson (Ballwin, MO).

\section{RESULTS}

\section{Mossy fibers innervate three distinct synapse types in the CA3 subfield}

Mossy fibers innervate both CA3 pyramidal cells and interneurons located within the stratum lucidum (Henze et al., 2000). Polyamine toxins, such as PhTx, are high-affinity antagonists of currents through calcium-permeable AMPA receptor channels that contain little or no GluR2 (Blaschke et al., 1993; Brackley et al., 1993; Herlitze et al., 1993; Washburn and Dingledine, 1996; Toth and McBain, 1998). In contrast, AMPA receptors that contain multiple copies of GluR2 form calcium-impermeable channels that are largely unaffected by polyamine toxins. Sensitivity to block by $\mathrm{PhTx}$ is therefore a useful parameter to determine the calciumpermeable nature of synaptically evoked EPSCs (Toth and McBain, 1998; Laezza et al., 1999). We have shown previously that mossy fibers innervate stratum lucidum interneurons via synapses comprised of either PhTx-sensitive, calcium-permeable AMPA receptors or PhTx-insensitive, calcium-impermeable AMPA receptors (Toth and McBain, 1998). However, although mossy fiber synaptic transmission onto CA3 pyramidal neurons has been well

\section{A. CA3 Pyramidal Neuron}

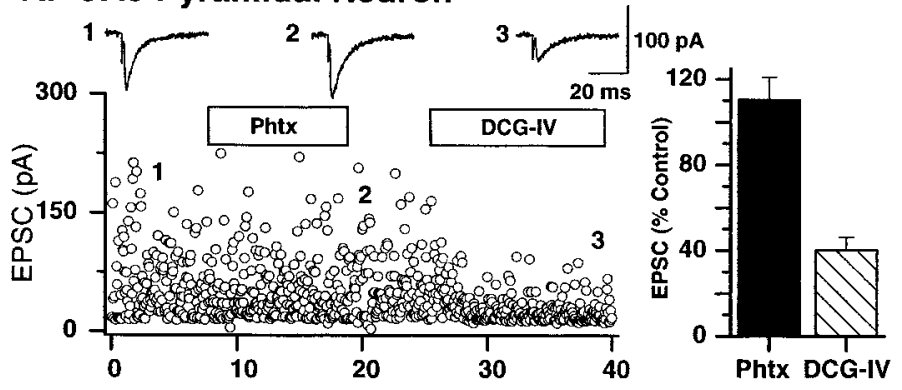

B. Interneuron

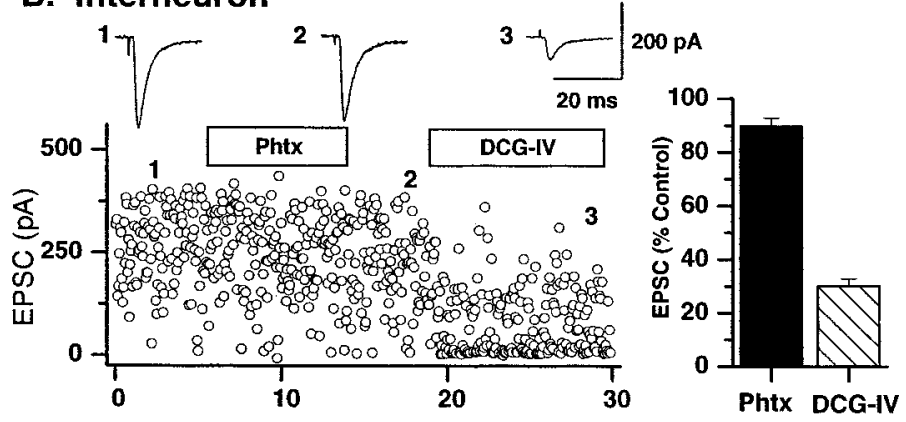

\section{Interneuron}

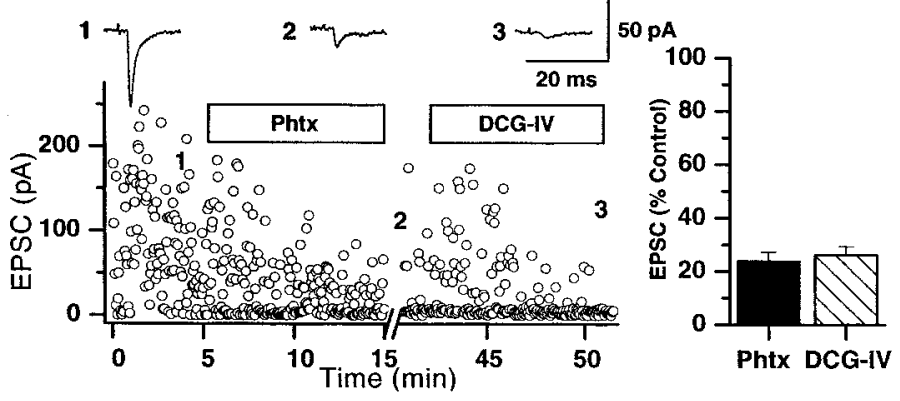

Figure 1. Calcium-permeable AMPA receptors are expressed only at mossy fiber $\rightarrow$ interneuron synapses. Representative recordings from a single pyramidal cell $(A)$ and two different interneurons $(B, C)$ illustrate the calcium-permeable nature of AMPA receptors expressed at mossy fiber synapses. Each dot represents a single mossy fiber-evoked EPSC at a frequency of $0.3 \mathrm{~Hz}$. $A, B$, Mossy fiber EPSCs on both the pyramidal cell $(A)$ and one subset of interneuron synapse $(B)$ were not blocked by PhTx ( $1 \mu \mathrm{M}$; duration of application indicated by open horizontal bar). Traces above the dot plots represent averages of 10 traces taken at time points indicated by the numbers $1-3$. DCG-IV $(0.1 \mu \mathrm{M})$ significantly reduced both EPSCs, confirming their mossy fiber nature. $C$, In contrast, mossy fiber EPSCs onto another interneuron were blocked by addition of PhTx. After a 15 min washout, EPSC amplitude partially returned to the control level. Subsequent application of DCG-IV $(0.1 \mu \mathrm{M})$ confirmed the mossy fiber origin of the EPSC. $A-C$, Right, Summary graphs show the average block caused by PhTx and DCG-IV in the three classes of synapses innervated by mossy fibers ( $n=6$ pyramidal cells; $n=18$ interneuron calciumimpermeable AMPA synapses; $n=14$ calcium-permeable interneuron AMPA synapses).

characterized, surprisingly, the PhTx sensitivity of their AMPA receptors has never been formally tested. Therefore we first determined the identity of AMPA receptors associated with mossy fiber-evoked EPSCs onto CA3 pyramidal neurons.

Mossy fiber-evoked EPSCs (stimulation frequency, 0.1-0.33 Hz, here and throughout the manuscript unless stated otherwise) onto pyramidal cells were insensitive to PhTx ( $1 \mu \mathrm{M}$; mean EPSC amplitude $=110.5 \pm 10.5 \%$ of control; $n=6 ; p=0.36$; Fig. $1 A)$. In contrast, when recordings were made from interneurons, $44 \%$ (14 of 32 representative cells) of mossy fiber-evoked EPSCs were blocked by $1 \mu \mathrm{M}$ PhTx $(23.8 \pm 3.5 \%$ of control; $p<0.0001$; Fig. $1 C)$, subsequently referred to as CP AMPA receptor synapses. The remaining $56 \%$ of interneurons had EPSCs that were only mod- 
estly blocked by PhTx $(86.1 \pm 5.5 \%$ of control; Fig. $1 B, C$; subsequently referred to as CI AMPA synapses).

Both pyramidal cells and interneurons in the CA3 region receive inputs not only from mossy fibers but also from CA3 pyramidal cell collaterals. Therefore, it was important to confirm in every experiment that the recorded EPSC originated from granule cell activation. Group II mGluRs are expressed exclusively on mossy fiber terminals and not on CA3 collaterals (Manzoni et al., 1995; Kamiya et al., 1996; Maccaferri et al., 1998; Toth and McBain, 1998). DCG-IV, a group II metabotropic glutamate receptor agonist, can therefore be used to identify unequivocally mossy fiber EPSCs. In all cases EPSCs were blocked by DCG-IV [0.1 $\mu \mathrm{M} ; 40.3 \pm 6 \%$ of control in pyramidal cells $(p<0.001) ; 30.2 \pm 2.7 \%$ of control in interneuron CI AMPA synapses $(p<0.001) ; 26.2 \pm 3.2 \%$ of control in interneuron CP AMPA synapses $(p<0.001)]$ confirming their mossy fiber origin (Fig. 1).

In every mossy fiber-interneuron recording reported in this study, the calcium-permeable nature of the AMPA receptor was determined by switching into PhTx. In addition, at the end of all recordings from both pyramidal neurons and inhibitory interneurons, evoked EPSCs were identified to be mossy fiber in origin, by confirming the DCG-IV sensitivity of the synaptic input.

\section{EPSC latencies are similar at all three synapse types}

The synapses within the CA3 subfield, i.e., strata pyramidale and lucidum, originate not only from mossy fiber axons but also from recurrent collaterals of CA3 pyramidal cells. In addition to receiving inputs from dentate gyrus granule cells, CA3 pyramids receive extensive input from neighboring pyramidal neurons (Gulyas et al., 1993), which also heavily innervate interneurons of the stratum lucidum (Toth and McBain, 1998). This complex circuitry enables polysynaptic innervation of both CA3 pyramidal neurons and inhibitory interneurons, which can complicate the electrophysiological study of "pure" mossy fiber transmission (for further discussion, see Henze et al., 2000). To confirm that synaptic inputs arise from monosynaptic mossy fiber innervation we next analyzed the latencies to EPSC onset in all three synapse types. Figure $2 A$ shows cumulative probabilities for the EPSC latencies at the three synapse types. Mean latencies in all analyzed experiments were in the range 1.5-3.0 msec, with an average of $2.0 \pm 0.1,2.2 \pm 0.1$, and $2.3 \pm 0.1 \mathrm{msec}$ for pyramidal neuron $(n=30)$, calciumimpermeable $(n=53)$, and calcium-permeable $(n=30)$ synapses, respectively. These values are similar to those of a previous report of mossy fiber-pyramidal cell EPSC latency (Jonas et al., 1993) and suggest that in all cases we were studying monosynaptic inputs to all three synapse types.

\section{Rise times and decay time constants}

Mossy fiber inputs onto CA3 pyramidal cells are made at synapses located within the first $100 \mu \mathrm{m}$ of the proximal apical dendrite. Previous studies of mossy fiber transmission onto principal cells have argued, on the basis of kinetics, that those EPSCs recorded on principal cells with rise times $\sim 1.0$ msec most likely reflect mossy fiber inputs (Jonas et al., 1993; Kapur et al., 1998; Yeckel et al., 1999; for further discussion, see Henze et al., 2000). In an extensive study of quantal parameters of mossy fiber transmission onto pyramidal neurons by Jonas et al. (1993) the averaged $20-80 \%$ rise time of unitary EPSCs was $\sim 0.6 \mathrm{msec}$, and the decay time constant of the EPSC was $\sim 6.0 \mathrm{msec}$. These and previous experiments however have imposed a kinetic criteria on the EPSC waveform $(20-80 \%$ rise time $<1 \mathrm{msec})$ to ensure that analysis was restricted to mossy fiber inputs. Thus data were reported for only those mossy fiber events with fast kinetics, raising the possibility that the full distribution of unitary mossy fiber EPSC kinetic parameters was not accurately described (Henze et al., 2000). The locations of mossy fiber inputs onto either type of inhibitory interneuron synapse are not known. Because the somatodendritic axis is parallel to the mossy fiber pathway, it makes it highly likely that mossy fiber inputs will arrive across the entire dendritic tree and not be restricted to a proximal portion of a dendrite as seen at pyramidal

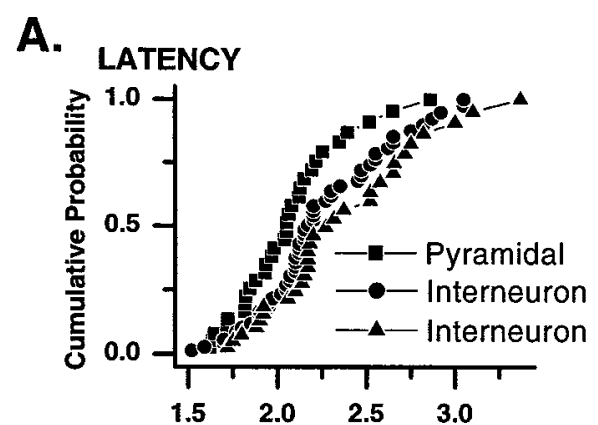

B.

$10-90 \%$ RISE TIME
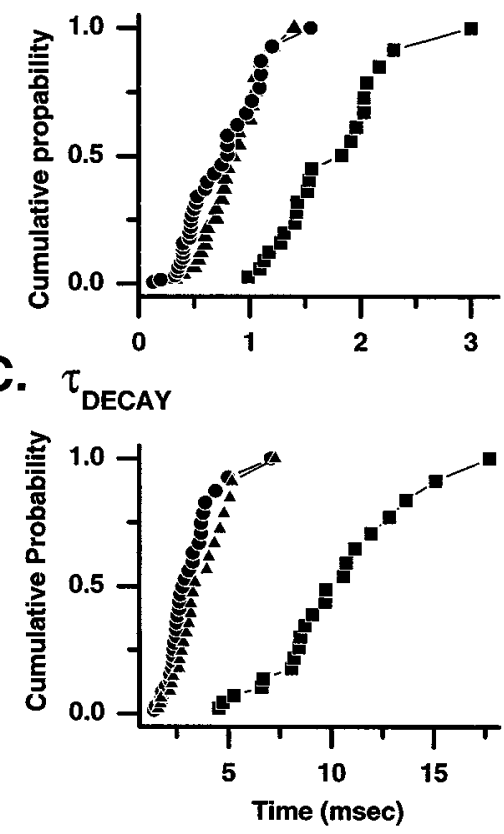

Figure 2. Latency, rise time, and decay time constant distributions of evoked EPSCs at three types of mossy fiber synapse. $A$, Cumulative probability plots are shown of latency distribution from a sample of mossy fiber-evoked EPSCs onto pyramidal neurons (squares), interneuron CI AMPA synapses (circles), and interneuron CP AMPA synapses (triangles). The range and mean latencies were not significantly different across all three synaptic types. The mean latencies from each experiment fell within the range $1.5-3.0 \mathrm{msec}$ at all three synapse types and suggest that in all cases EPSCs were monosynaptic in origin. $B, C$, Cumulative probability plots of the $10-90 \%$ rise time $(B)$ and decay time constant $(C)$ reveal that EPSCs at both interneuron synapse types generally have briefer rise times and decay times than do those observed at equivalent synapses onto CA3 pyramidal neurons.

cell synapses. This makes the use of rigid kinetic criteria to identify mossy fiber EPSCs problematic. Because DCG-IV selectively blocks mossy fiber inputs, we have included kinetic data from all DCG-IV-sensitive EPSCs at all three synapse types. Figure 2, $B$ and $C$, shows the cumulative probability plots of the $10-90 \%$ rise time and decay time constant of EPSCs recorded from all three synapse types. The mean $10-90 \%$ rise time and decay time constant were $1.7 \pm 0.1$ and $9.6 \pm 0.7 \mathrm{msec}(n=21)$ for mossy fiber EPSCs onto pyramidal neurons, $0.6 \pm 0.1$ and $2.8 \pm 0.2 \mathrm{msec}(n=$ 33) for interneuron CI AMPA EPSCs, and $0.8 \pm 0.1$ and $3.4 \pm 0.3$ msec $(n=24)$ for interneuron CP AMPA EPSCs, respectively. In general interneuron EPSCs at both CP AMPA and CI AMPA synapses possessed shorter $10-90 \%$ rise times and decay time constants than did CI AMPA synapses onto pyramidal neurons. The reasons for this are unclear at present but may reflect a different subunit composition of AMPA receptors on interneurons versus pyramidal cells, the reduced asynchrony of release at the more simple interneuron synapses than the complex asynchronous 
release at multiple release sites associated with larger mossy boutons, or alternatively better voltage-clamping of EPSCs on the more compact interneurons. Future experiments are required to elucidate fully the source of this variability.

\section{The response to trains of stimuli can be either facilitating or depressing at interneuron synapses but only facilitating at pyramidal neuron synapses}

In cortical and hippocampal circuits repetitive activation of the presynaptic axon can lead to synaptic responses that undergo either progressive increases (facilitation) or decreases (depression) in amplitude. Synapses expressing either depressing or facilitating postsynaptic responses are thought to play distinct roles in a given neuronal network. Whether a synapse is facilitating or depressing during high-frequency stimulation depends on many factors (e.g., $\mathrm{Ca}^{2+}$ dynamics in the presynaptic terminal, differential expression of voltage-gated channels in the presynaptic terminal, the depletability of the readily releasable pool, presynaptic neurotransmitter autoreceptors, neurotransmitter concentration vs time profile, degree of transmitter spillover, and postsynaptic receptor desensitization) (for review, see Zucker, 1989, 1999; Toth and McBain, 2000).

Short-term plasticity at the mossy fiber synapse onto CA3 pyramidal neurons differs significantly from that observed at most cortical or hippocampal synapses. Mossy fiber synapses onto CA3 pyramidal neurons exhibit high levels of facilitation (two times greater than that at associational/commissural synapses) in response to either paired pulses or brief trains of stimulation (Salin et al., 1996). This great degree of short-term plasticity likely arises from the numerous release sites with low initial release probabilities within a single mossy bouton, consequently making this synapse well suited to exert a powerful short-term influence over CA3 pyramidal neuron activity. In contrast, mossy fiber synapses onto interneurons comprise a single release site (Acsady et al., 1998), and whether a similar degree of short-term facilitation exists at these synapses remains to be determined.

To determine short-term plasticity at the three different types of synapse, mossy fiber inputs were stimulated with trains of five events at $20 \mathrm{~Hz}$ (repeated 10 times at $30 \mathrm{sec}$ intervals). This stimulus paradigm was chosen because it allowed brief trains of stimuli to be used that did not induce long-lasting changes in synaptic transmission at pyramidal cell or interneuron CP AMPA synapses. The long time interval between trains $(30 \mathrm{sec})$ minimized frequency-dependent changes in synaptic events associated with mossy fiber stimulation (Scanziani et al., 1997) (see below for further details).

In all cases, mossy fiber-pyramidal neuron EPSCs displayed short-term facilitation in response to repetitive stimulation of mossy fiber inputs (Fig. 3A). A comparison of the first EPSC amplitude with the fifth EPSC amplitude $\left(\mathrm{EPSC}_{5} / \mathrm{EPSC}_{1}\right)$ in the train revealed a mean facilitation of $343.9 \pm 52.6 \%(n=22$ cells $)$. In contrast both CI AMPA and CP AMPA synapses displayed either facilitation or depression in response to the $20 \mathrm{~Hz}$ train (Fig. $3 B, C)$. Sixty-three percent of interneuron CI AMPA synapses showed depression of $\mathrm{EPSC}_{5} / \mathrm{EPSC}_{1}$ (mean $\mathrm{EPSC}_{5}=61.3 \pm 4.2 \%$ of $\mathrm{EPSC}_{1} ; n=29$ cells). The remaining $37 \%$ of interneuron $\mathrm{CI}$ AMPA synapses showed facilitation (mean $\mathrm{EPSC}_{5}=156.7 \pm$ $13.5 \%$ of $\left.\mathrm{EPSC}_{1} ; n=17\right)$. Similarly $46 \%$ of interneuron CP AMPA synapses were depressing (mean $\mathrm{EPSC}_{5}=59.8 \pm 6.8 \%$ of $\mathrm{EPSC}_{1}$; $n=15$ ), whereas the remainder were facilitating (mean $\mathrm{EPSC}_{5}=$ $172.2 \pm 14.9 \%$ of $\mathrm{EPSC}_{1} ; n=13$ ). Note that although a large number of interneuron synapses demonstrated facilitation during the $20 \mathrm{~Hz}$ train, the magnitude of the mean facilitation was significantly lower than that seen at mossy fiber $\rightarrow$ pyramidal neuron synapses.

\section{Effects of lowering or increasing presynaptic transmitter release probability on short-term plasticity}

The peak amplitude of EPSCs at all three mossy fiber synapses demonstrated a large trial-to-trial variability (e.g., see Figs. 1, 9),
A. CA3 Pyramidal Neuron
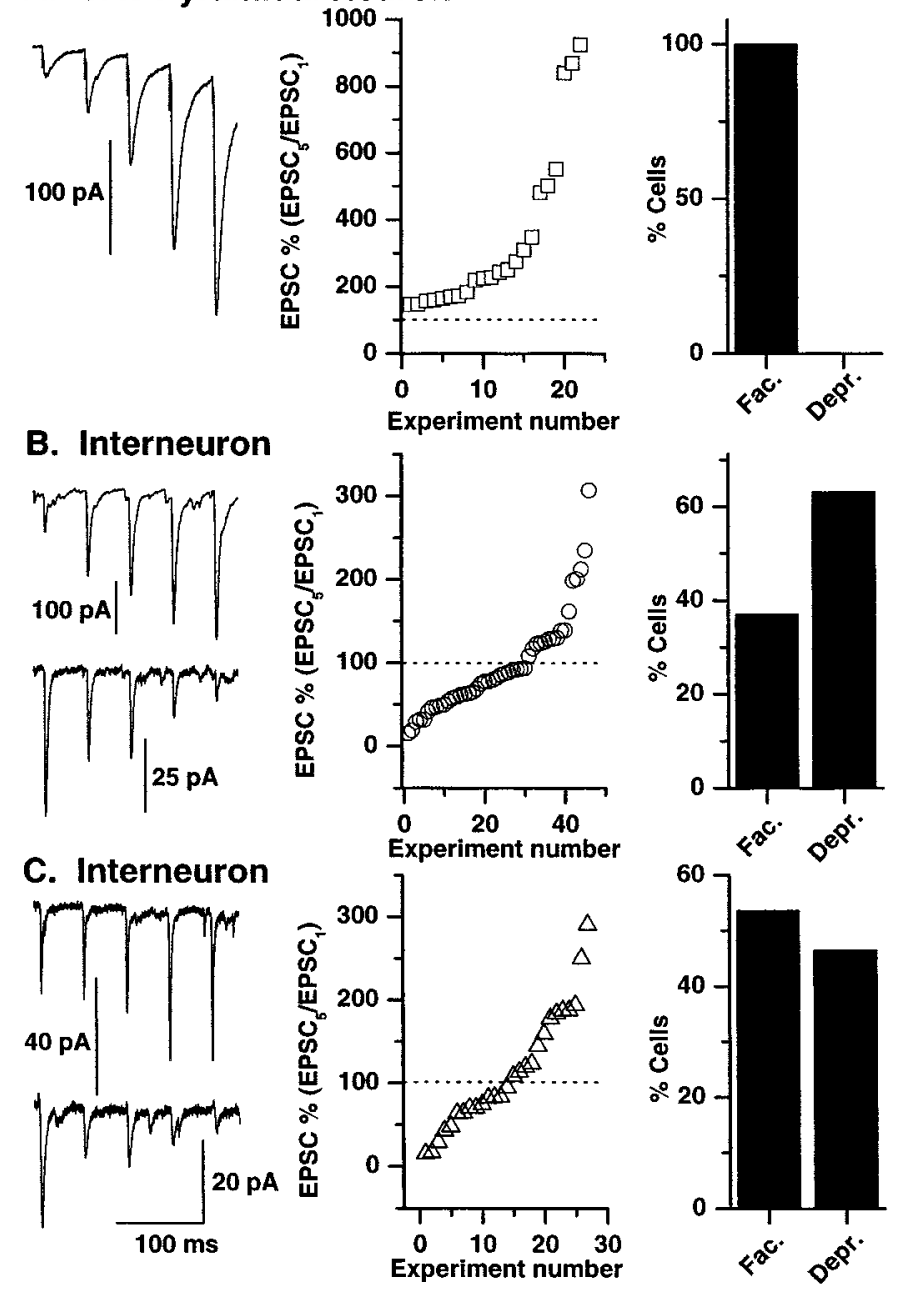

Figure 3. Short-term facilitation and depression in response to brief trains of high-frequency stimuli at three types of mossy fiber synapse. $A$, All mossy fiber $\rightarrow$ pyramidal synapses demonstrate marked short-term facilitation in response to a brief high-frequency train $(5$ pulses; $20 \mathrm{~Hz})$. Left, A representative trace from a mossy fiber $\rightarrow$ pyramidal neuron recording (average of 10 traces) in response to a brief high-frequency stimulus is shown. Middle, Mean $\mathrm{EPSC}_{5} / \mathrm{EPSC}_{1}$ data from all cells show that all mossy fiber $\rightarrow$ pyramidal cell synapses demonstrated facilitation in response to a brief high-frequency train of stimuli; i.e., $\mathrm{EPSC}_{5} / \mathrm{EPSC}_{1}$ ratio is $>100 \%$. Right, A histogram of the percentage of mossy fiber $\rightarrow$ pyramidal cell synapses that show facilitation (Fac) versus depression (Depr) in response to the $20 \mathrm{~Hz}$ stimulus train $(n=22$ representative recordings) is shown. $B, C$, Both interneuron CI AMPA synapses $(B)$ and CP AMPA synapses $(C)$ can show either facilitation or depression in response to the $20 \mathrm{~Hz}$ stimulus paradigm. Left, In both $B$ and $C$ each trace is an average of 10 representative facilitating or depressing responses, each obtained from a different mossy fiber $\rightarrow$ interneuron recording. Middle, Right, The distribution and percentage facilitation and depression in all mossy fiber $\rightarrow$ interneuron recordings are shown $(B, n=46 ; C, n=28)$.

and some stimuli evoked no detectable EPSC (i.e., failures) (see also Jonas et al., 1993). Similarly, the EPSCs evoked in response to the $20 \mathrm{~Hz}$ stimulus train were highly variable, with failures occurring at any of the five pulses in the train. Furthermore at mossy fiber $\rightarrow$ interneuron synapses, although the averaged response to the $20 \mathrm{~Hz}$ train was found to be facilitating or depressing, single trials often showed facilitation of the $\mathrm{EPSC}_{5} / \mathrm{EPSC}_{1}$ despite the mean $\mathrm{EPSC}_{5} / \mathrm{EPSC}_{1}$ showing depression (and vice versa). Debanne et al. (1996) demonstrated using connected pairs of pyramidal neurons that paired-pulse facilitation was observed with a higher probability when the first EPSC was small whereas paired pulse depression (PPD) was observed when the first EPSC was large. Furthermore the likelihood of observing PPD was greater when the release probability was high (i.e., by altering the $\left[\mathrm{Mg}^{2+}\right] /\left[\mathrm{Ca}^{2+}\right]$ ratio) and 
A. CA3 Pyramidal Neuron

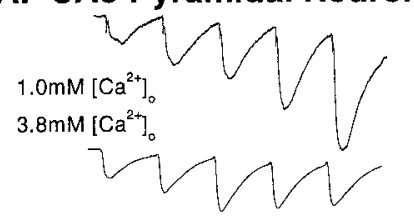

\section{B. Interneuron}

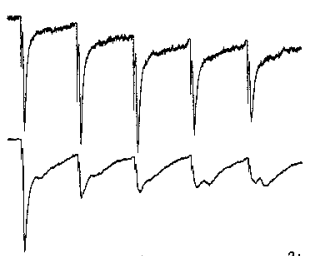

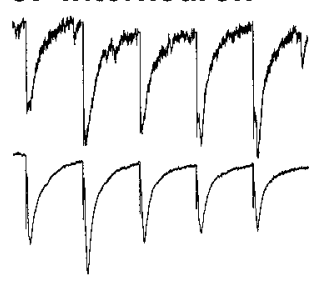

C. Interneuron
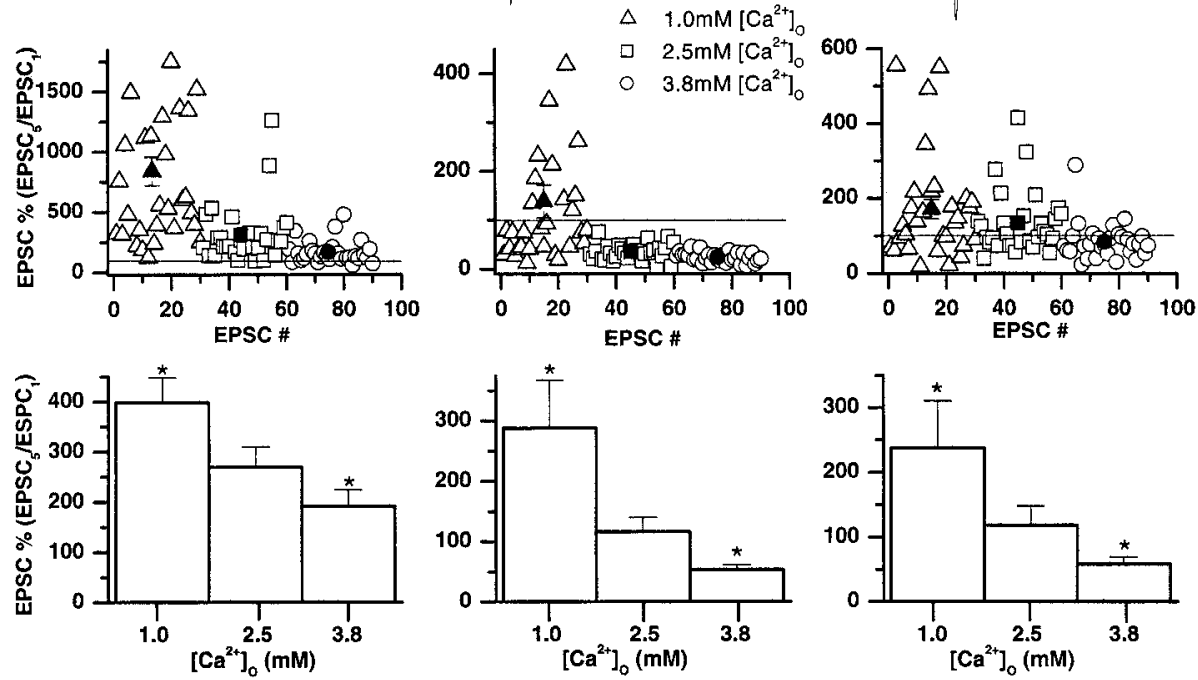

Figure 4. Short-term plasticity is determined by the initial presynaptic transmitter release probability. Representative experiments from a mossy fiber $\rightarrow$ pyramidal neuron synapse $(A)$, interneuron CI AMPA synapse $(B)$, and CP AMPA synapse $(C)$ showing that the degree of facilitation or depression is influenced by the external $\mathrm{Ca}^{2+} /$ $\mathrm{Mg}^{2+}$ ratio. Top, Averages of 30 EPSCs evoked in response to a brief train of stimuli $(20 \mathrm{~Hz} ; 5$ pulses repeated at $30 \mathrm{sec}$ intervals) in $1.0 \mathrm{~mm} \mathrm{Ca}{ }^{2+} / 3.0$ $\mathrm{mM} \mathrm{Mg}^{2+}$ (top traces) and $3.8 \mathrm{mM} \mathrm{Ca}{ }^{2+} / 0.8 \mathrm{~mm}$ $\mathrm{Mg}^{2+}$ (bottom traces). The first EPSC amplitudes have been normalized to allow comparison of the degree of facilitation or depression under both recording conditions. At all three synapses, increasing the presynaptic release probability by elevating external $\mathrm{Ca}^{2+}$ decreased the $\mathrm{EPSC}_{5} /$ $\mathrm{EPSC}_{1}$ ratio. Middle, Plots of the fifth EPSC amplitude $\left(\mathrm{EPSC}_{5}\right)$ relative to the $\mathrm{EPSC}_{1}$ amplitude for individual data points in three $\mathrm{Ca}^{2+}$ / $\mathrm{Mg}^{2+}$ conditions from single experiments (same cells shown in top panels). Under conditions of normal $\mathrm{Ca}^{2+} / \mathrm{Mg}^{2+}(2.5 \mathrm{~mm} / 1.25 \mathrm{~mm}$, respectively; squares), $0 \%$ of mossy fiber $\rightarrow$ pyramidal neuron EPSCs showed depression of the $\mathrm{EPSC}_{5} / \mathrm{EPSC}_{1}$ ratio (i.e., $\mathrm{EPSC}_{5} / \mathrm{EPSC}_{1}$ ratio was never $<100 \%$ ). In contrast, $100 \%$ of interneuron CI AMPA synapse EPSCs and $50 \%$ of the CP AMPA synapse EPSCs demonstrated $\mathrm{EPSC}_{5} / \mathrm{EPSC}_{1}$ ratios of $<100 \%$. When the release probability was reduced by decreasing external $\mathrm{Ca}^{2+}(1.0 \mathrm{mM})$ and elevating $\mathrm{Mg}^{2+}(3.0 \mathrm{~mm})$, greater facilitation of $\mathrm{EPSC}_{5} /$ EPSC $_{1}$ was seen in all trials at the mossy fiber $\rightarrow$ pyramidal neuron synapse (triangles). Similarly, the number of trials showing a depression of $\mathrm{EPSC}_{5} / \mathrm{EPSC}_{1}$ decreased to $63 \%$ at the interneuron CI AMPA synapse and $36 \%$ at the CP AMPA synapse EPSCs. In contrast, when the release probability was increased by elevating external Ca ${ }^{2+}$ $(3.8 \mathrm{~mm})$ and decreasing $\mathrm{Mg}^{2+}(0.8 \mathrm{mM})$, facilitation was observed in only $84 \%$ of trials at the mossy fiber $\rightarrow$ pyramidal neuron synapse, $0 \%$ of the interneuron CI AMPA synapse EPSCs, and $20 \%$ of CP AMPA synapse EPSC s (circles). The mean response under low, normal, and high Ca ${ }^{2+}$ conditions is shown by the solid triangle, solid square, and solid circle, respectively. Where error bars are absent, the error bar is less than the symbol size. Bottom, Mean data for all experiments in three external $\mathrm{Ca}^{2+} / \mathrm{Mg}^{2+}$ conditions $(n=6$ for pyramidal neurons, 7 for interneuron CI AMPA synapses, and 6 for CP AMPA synapses). Note that the mean $\mathrm{EPSC}_{5} / \mathrm{EPSC}_{1}$ ratio was facilitating at mossy fiber $\rightarrow$ pyramidal neuron synapses in all recording conditions, whereas facilitation of the $\mathrm{EPSC}_{5} / \mathrm{EPSC}_{1}$ ratio at interneuron synapses was most prominent only under conditions of reduced release probability. Asterisks indicate data significantly different from $\left[\mathrm{Ca}^{2+}\right] \mathrm{o}=2.5 \mathrm{~mm}$ condition.

smaller when the release probability was decreased (Debanne et al., 1996). Therefore, we next performed experiments in solutions containing an altered $\left[\mathrm{Mg}^{2+}\right] /\left[\mathrm{Ca}^{2+}\right]$ ratio to determine whether the trial-to-trial variability and the facilitating or depressing nature of mossy fiber transmission were a function of release probability.

Decreasing the $\mathrm{Ca}^{2+}$ concentration to $1.0 \mathrm{~mm}$ and increasing the $\mathrm{Mg}^{2+}$ concentration to $3.0 \mathrm{~mm}$, conditions that are known to reduce the probability of transmitter release at the neuromuscular junction and central synapses (delCastillo and Katz, 1954; Creager et al., 1980; Jonas et al., 1993; Manabe et al., 1993; Debanne et al., 1996), reduced the average size of the evoked EPSC at all three mossy fiber synapses (Fig. 4). Lowering the $\mathrm{Ca}^{2+} / \mathrm{Mg}^{2+}$ ratio reduced the mean peak current from $100.2 \pm 25$ to $25.5 \pm 5.5 \mathrm{pA}$ $($ mean reduction $=74.5 \%), 39.0 \pm 8.4$ to $19.0 \pm 4.3 \mathrm{pA}$ (mean reduction $=51.3 \%$ ), and $66.4 \pm 20.1$ to $20.1 \pm 7.0 \mathrm{pA}$ (mean reduction $=70.2 \%$ ) at mossy fiber $\rightarrow$ pyramidal cell, $\rightarrow$ interneuron CI AMPA, and $\rightarrow$ interneuron CP AMPA synapses, respectively. Similarly increasing the $\mathrm{Ca}^{2+} / \mathrm{Mg}^{2+}$ ratio $(3.8 / 0.8 \mathrm{~mm}$, respectively) increased the mean peak current from $100.2 \pm 25$ to $140.3 \pm$ $29.7 \mathrm{pA}($ mean increase $=140.2 \%), 39.0 \pm 8.4$ to $73.8 \pm 10.7 \mathrm{pA}$ (mean increase $=189 \%$ ), and $65.0 \pm 23.7$ to $96.1 \pm 33.6 \mathrm{pA}$ (mean increase $=147.8 \%$ ) at mossy fiber $\rightarrow$ pyramidal cell, $\rightarrow$ interneuron CI AMPA, and $\rightarrow$ interneuron CP AMPA synapses, respectively.

We then studied the effects of altering presynaptic release probability on short-term plasticity at each synapse type. Trains of five stimuli delivered at $20 \mathrm{~Hz}$ (repeated 30 times at $15 \mathrm{sec}$ intervals) were delivered in conditions of "low" $\left(1.0 \mathrm{mM} \mathrm{Ca}{ }^{2+} / 3.0 \mathrm{mM} \mathrm{Mg}^{2+}\right)$, "normal" (2.5 mM Ca $\left.{ }^{2+} / 1.25 \mathrm{~mm} \mathrm{Mg}^{2+}\right)$, and "high" (3.8 mM $\mathrm{Ca}^{2+} / 0.8 \mathrm{~mm} \mathrm{Mg}{ }^{2+}$ ) release probability (Fig. 4). In each recording, solutions containing altered $\mathrm{Ca}^{2+} / \mathrm{Mg}^{2+}$ ratios were delivered in a randomized order. Figure 4 illustrates recordings from representative experiments from each of the three mossy fiber synapse types. When $\mathrm{Ca}^{2+}$ was elevated and $\mathrm{Mg}^{2+}$ reduced, i.e., the release probability was increased, the $\mathrm{EPSC}_{5} / \mathrm{EPSC}_{1}$ ratio was reduced at all three synapses. Although transmission at mossy fiber-pyramidal neurons continued to show facilitation in response to the $20 \mathrm{~Hz}$ train $\left(\right.$ mean $\mathrm{EPSC}_{5} / \mathrm{EPSC}_{1}$ ratio $=191.0 \pm 33$ vs $269.2 \pm 40.2 \%$ under normal conditions; $n=6$ ), both interneuron CI AMPA and CP AMPA synapses invariably demonstrated depression of the $\mathrm{EPSC}_{5} / \mathrm{EPSC}_{1}$ ratio (CI AMPA synapses, mean $\mathrm{EPSC}_{5} / \mathrm{EPSC}_{1}$ ratio $=53.6 \pm 8.0$ vs $116.3 \pm 23.7 \%$ under normal conditions; $n=$ 7; CP AMPA synapses, mean $\mathrm{EPSC}_{5} / \mathrm{EPSC}_{1}$ ratio $=61.5 \pm 10.5 \mathrm{vs}$ $117.2 \pm 29.8 \%$ under normal conditions; $n=6$ ).

When the release probability was then lowered $\left(1.0 \mathrm{~mm} \mathrm{Ca}^{2+} / 3.0\right.$ $\mathrm{mM} \mathrm{Mg}^{2+}$ ), the mean $\mathrm{EPSC}_{5} / \mathrm{EPSC}_{1}$ ratio was significantly greater at all three synapses compared with that in control normal $\mathrm{Ca}^{2+}$ / $\mathrm{Mg}^{2+}$ conditions (Fig. 4). The mean $\mathrm{EPSC}_{5} / \mathrm{EPSC}_{1}$ ratio at mossy fiber $\rightarrow$ pyramidal cell synapses, $\rightarrow$ interneuron CI AMPA synapses, and $\rightarrow$ CP AMPA synapses was $397.9 \pm 50.2 \%(n=6), 287.7 \pm$ $80.1 \%(n=7)$, and $233.5 \pm 79.5 \%$ of control values (i.e., normal $\mathrm{Ca}^{2+} / \mathrm{Mg}^{2+}$ conditions), respectively. These data demonstrate that the number of trials showing facilitation was greatest when release probability was low and $\mathrm{EPSC}_{1}$ amplitude was small. Conversely the likelihood of observing synaptic depression in response to a train of stimuli was greatest when release probability was increased, consistent with the increase in amplitude of the first EPSC in the train.

\section{Polyamine-dependent facilitation of synaptic transmission exists at only interneuron CP AMPA synapses}

Calcium-permeable AMPA receptors are tonically blocked by endogenous intracellular polyamines (Bowie and Mayer, 1995; Kamboj et al., 1995; Koh et al., 1995). This intracellular block by polyamines underlies the inward rectification of the current-voltage relationship associated with GluR2-lacking AMPA receptors. 
Relief of block by intracellular polyamines is both use and voltage dependent (Bowie et al., 1998; Rozov et al., 1998) and endows CP AMPA receptors with a postsynaptic mechanism for the short-term enhancement of synaptic gain (McBain, 1998; Rozov and Burnashev, 1999).

We next wanted to determine whether such a mechanism of short-term plasticity existed at mossy fiber $\rightarrow$ interneuron CP AMPA synapses. Brief trains of stimuli $(20 \mathrm{~Hz} ; 5$ pulses; 10 times; repeated every $30 \mathrm{sec}$ ) identical to those described above were delivered to mossy fiber inputs to all three synapse types. In this set of experiments EPSCs were collected at postsynaptic holding potentials of -80 and $-20 \mathrm{mV}$. Because polyamine block of $\mathrm{CP}$ AMPA receptors is maximal at more positive holding potentials and the mechanism of polyamine unblock is use dependent, we hypothesized that the degree of facilitation recorded at $-20 \mathrm{mV}$ would be greater than that observed at $-80 \mathrm{mV}$ at which polyamine affinity would be lowest. Figure 5 shows that in all recordings made from mossy fiber $\rightarrow$ interneuron CP AMPA synapses the degree of facilitation at $-20 \mathrm{mV}$ is indeed greater than that observed at -80 $\mathrm{mV}$. The ratio of the $\mathrm{EPSC}_{5} / \mathrm{EPSC}_{1}$ evoked by the $20 \mathrm{~Hz}$ train was $108.7 \pm 23.6 \%$ at $-80 \mathrm{mV}$ and $181.2 \pm 39.1 \%$ at $-20 \mathrm{mV}(n=9$; $p=0.005)$. Because the intracellular polyamine block of AMPA receptors is selective for GluR2-lacking, CP AMPA synapses, one would expect no voltage dependence to the degree of facilitation (or depression) seen at either CI AMPA synapses on CA3 pyramidal neurons or inhibitory interneurons. This was found to be the case. The degree of facilitation at mossy fiber $\rightarrow$ pyramidal neuron synapses was $235.1 \pm 24.6$ and $238.4 \pm 26.7 \%(n=7 ; p=0.8)$ at -80 and $-20 \mathrm{mV}$, respectively. Similarly the $\mathrm{EPSC}_{5} / \mathrm{EPSC}_{1}$ ratio was $87.8 \pm 14.6$ versus $86.4 \pm 12.9 \%$ at -80 and $-20 \mathrm{mV}$, respectively, for mossy fiber $\rightarrow$ interneuron CI AMPA synapses $(n=10 ; p=0.7)$.

Finally recordings were made from mossy fiber $\rightarrow$ CP AMPA synapses using electrodes filled with intracellular solution lacking added spermine and including $10 \mathrm{~mm}$ ATP to chelate endogenous polyamines (Bahring et al., 1997). Under these conditions voltagedependent facilitation was lost, and the degree of facilitation observed at both voltages was similar (mean facilitation $=143.9 \pm$ $51.7 \%$ at $-80 \mathrm{mV}$ and $126.7 \pm 34 \%$ at $-20 \mathrm{mV} ; n=4 ; p=0.9$ ). These data underscore that the voltage-dependent facilitation seen at interneuron CP AMPA synapses results from the use- and voltage-dependent unblock of spermine from GluR2-lacking AMPA receptors.

\section{Frequency-dependent short-term plasticity}

A property that sets mossy fiber $\rightarrow$ pyramidal neuron transmission apart from other cortical and hippocampal synapses is their ability to integrate granule cell spiking activity over a broad dynamic range of frequencies. Salin et al. (1996) demonstrated that facilitation of mossy fiber transmission occurred at presynaptic stimulation frequencies as low as once every $40 \mathrm{sec}$ and reached a magnitude of $\sim 600 \%$ of control at $0.33 \mathrm{~Hz}$. In contrast, facilitation of transmission at associational/commissural synapses occurred only at frequencies greater than once every $10 \mathrm{sec}$ and reached a magnitude of $\sim 125 \%$ of control. The greater degree of frequencydependent facilitation observed at mossy fiber $\rightarrow$ pyramidal cell synapses results from large rises in intraterminal calcium concentrations and activation of $\mathrm{Ca}^{2+} /$ calmodulin-dependent kinase II (Salin et al., 1996). In the next set of experiments we used an experimental design similar to that described by Salin et al. (1996) to determine whether a similar degree of frequency-dependent facilitation exists at mossy fiber $\rightarrow$ interneuron synapses. Control stimulation frequency was set at $0.05 \mathrm{~Hz}$, and 15 events were collected. The stimulation frequency was then incrementally increased, and 15 events were collected at $0.1,0.2,0.33,1,2,3$, and 4 $\mathrm{Hz}$; the stimulation frequency was then returned to $0.05 \mathrm{~Hz}$ to ensure that no lasting change in synaptic efficacy had occurred. The averaged data at each frequency were normalized to that obtained at $0.05 \mathrm{~Hz}$ (Salin et al., 1996).
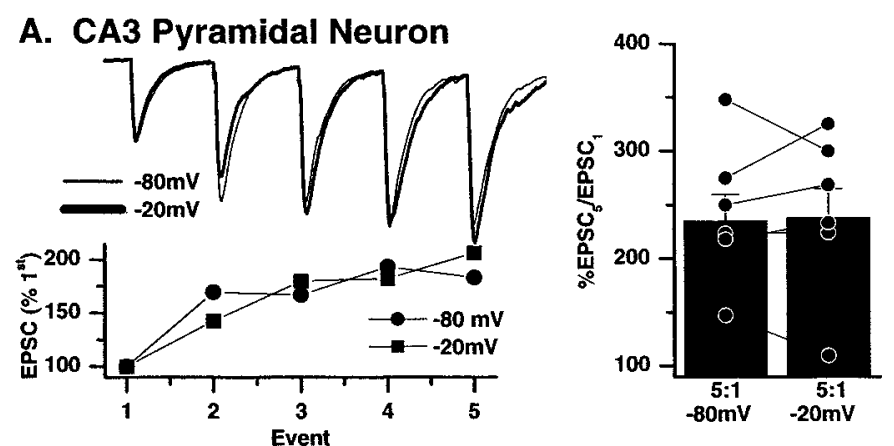

\section{B. Interneuron}
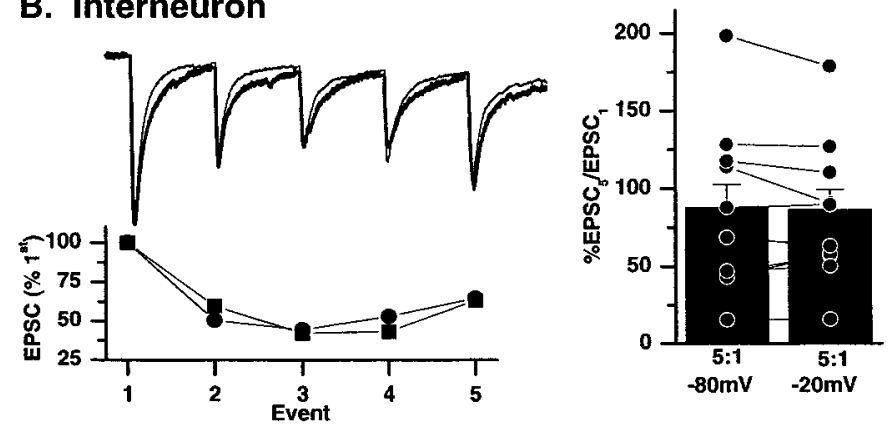

\section{Interneuron}
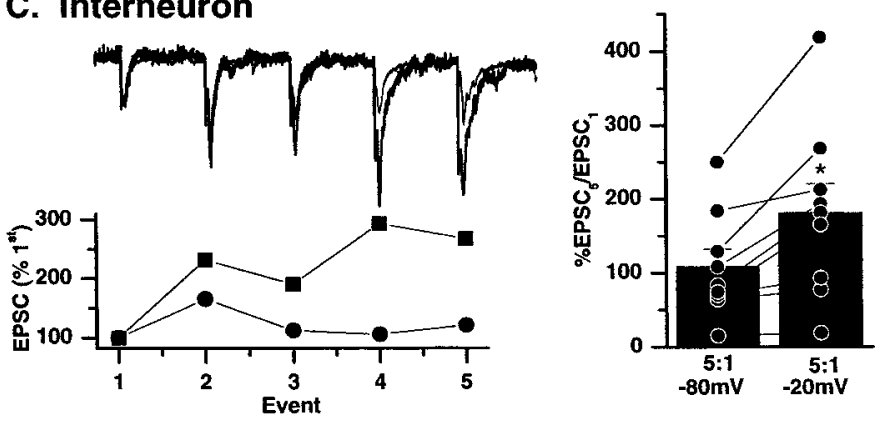

Figure 5. Voltage-dependent relief from polyamine block causes enhanced facilitation at calcium-permeable AMPA synapses at depolarized potentials. Trains of five mossy fiber EPSCs were evoked at $20 \mathrm{~Hz}$ on pyramidal cells $(A)$, calcium-impermeable AMPA synapses of interneurons $(B)$, and calcium-permeable synapses of interneurons $(C)$. The stimulation pattern was repeated 10 times at two holding potentials $(-80$ and $-20 \mathrm{mV})$. Each panel shows a representative experiment from each synapse type. A, B, Left, Trains of EPSCs at CI AMPA synapses on both pyramidal neurons $(A)$ and interneurons $(B)$ recorded at $-80 \mathrm{mV}$ (circles) and $-20 \mathrm{mV}$ (squares) are superimposable when scaled to the first EPSC in the train, indicating a similar degree of facilitation at both voltages. Right, Summary histograms show the ratio of the fifth and first EPSC amplitudes in the train at the two holding potentials in all experiments. No significant difference was observed in the mean ratio of $\mathrm{EPSC}_{5} / \mathrm{EPSC}_{1}$ measured at -20 or $-80 \mathrm{mV}$ (histogram vertical bars), indicating that the degree of facilitation or depression is similar at both voltages in these synapses. $C$, Left, In contrast, at mossy fiber $\rightarrow$ interneuron CP AMPA synapses, normalizing the first EPSCs in the trains evoked at both -20 and $-80 \mathrm{mV}$ reveals a greater degree of facilitation in EPSCs evoked at $-20 \mathrm{mV}$. Right, Summary histogram shows data from nine experiments in which regardless of whether the synapse was facilitating or depressing the $\mathrm{EPSC}_{5} / \mathrm{EPSC}_{1}$ ratio was always larger at more positive $(-20 \mathrm{mV})$ potentials at which the intracellular polyamine block is relieved. The asterisk indicates that mean percentage of EPSCs/EPSC is significantly different from $-80 \mathrm{mV}$ data.

In eight of eight mossy fiber $\rightarrow$ pyramidal neuron recordings, significant facilitation was observed at $0.1 \mathrm{~Hz}$ (Fig. 6). Maximal facilitation occurred at $4 \mathrm{~Hz}$ and was $1049 \pm 261 \%$ of control $(n=$ $8)$. In contrast, the degree of frequency-dependent facilitation observed at both types of mossy fiber $\rightarrow$ interneuron synapse was markedly less than that seen at mossy fiber $\rightarrow$ pyramidal neurons. At both interneuron CI AMPA and CP AMPA synapses, significant facilitation was not observed until frequencies $\sim 1 \mathrm{~Hz}(1 \mathrm{~Hz}$ for CI AMPA synapse; $2 \mathrm{~Hz}$ for CP AMPA synapses; Fig. 7 and data not 


\section{CA3 Pyramidal Neuron}
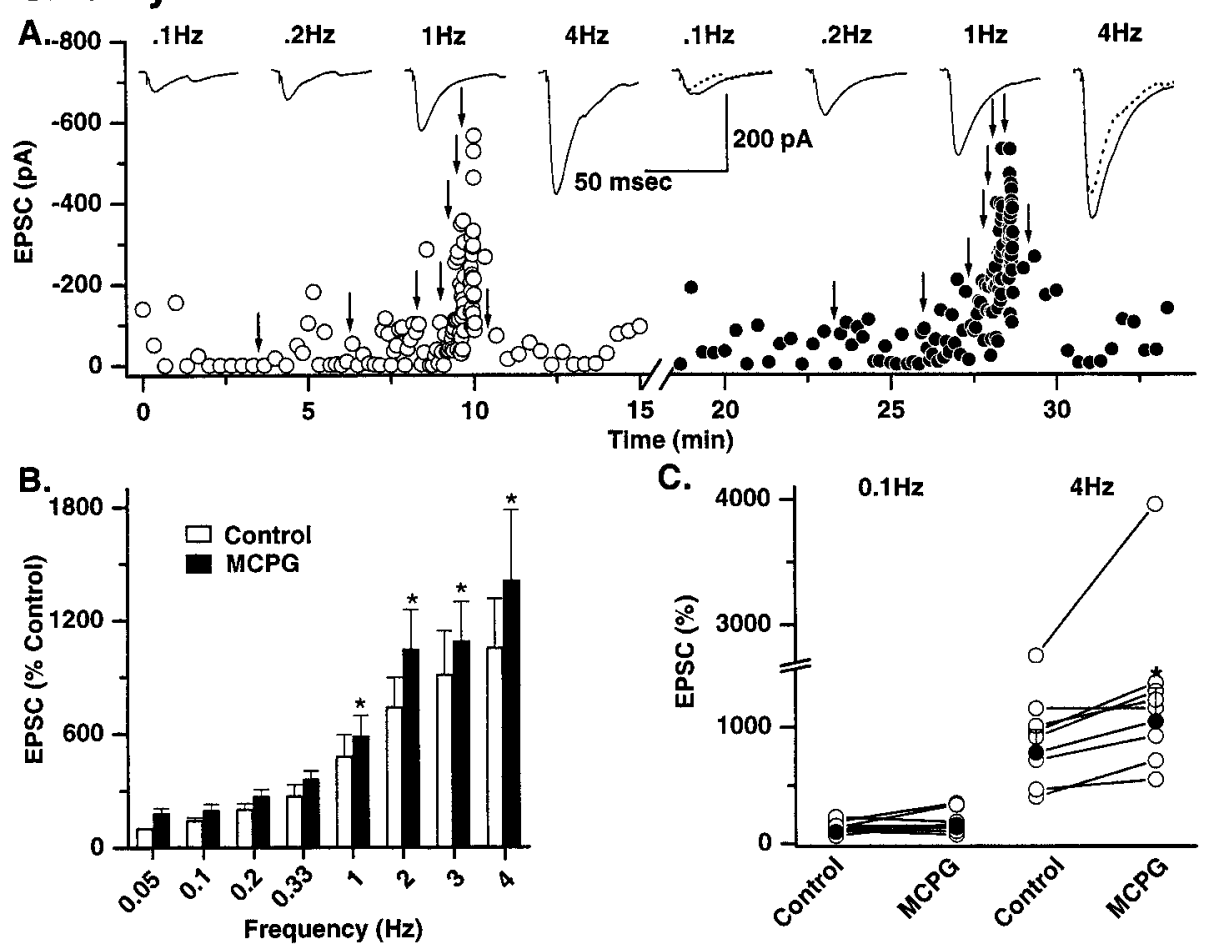

Figure 6. Mossy fiber $\rightarrow$ pyramidal cell synapses: frequency-dependent facilitation and modulation by metabotropic glutamate receptors. $A$, A single representative experiment shows frequency-dependent facilitation of mossy fiber $\rightarrow$ pyramidal neuron EPSC amplitude. Left, Fifteen EPSCs were evoked under control conditions (open circles) at a starting frequency of $0.05 \mathrm{~Hz}$, the stimulation frequency was then increased (indicated by arrows) to $0.1,0.2,0.33$, $1,2,3$, and $4 \mathrm{~Hz}$, and 15 events were captured at each frequency. Averaged traces ( 15 events) at four sample frequencies are shown above the dot plot. The stimulus frequency was then returned to 0.05 $\mathrm{Hz}$ to ensure that no long-lasting change in synaptic efficacy had occurred as a result of high-frequency stimulation. Right, The solution was then exchanged for one containing MCPG $(0.5 \mathrm{mM})$, and the experiment was repeated (solid circles). MCPG enhanced the amplitude of mossy fiber $\rightarrow$ pyramidal neuron EPSCs only at frequencies of $1 \mathrm{~Hz}$ and above. Traces above the dot plot show averaged EPSCs from four representative frequencies. The EPSC amplitudes in the control (dotted traces) are superimposed on the 0.1 and $4 \mathrm{~Hz}$ data to illustrate the frequency-dependent enhancement of EPSCs by MCPG. $B$, Summary histogram from eight experiments shows the mean EPSC facilitation (data normalized to $0.05 \mathrm{~Hz}$ data). MCPG significantly enhances EPSC amplitude in all experiments only at 1 $\mathrm{Hz}$ and above. C, Dot plot of data from all experiments at 0.1 and $4 \mathrm{~Hz}$ illustrates that despite the wide range of frequency-dependent facilitation across all experiments MCPG significantly enhanced transmission at high and not low frequencies in any experiment. Asterisks indicate data significantly different from equivalent control data.
Figure 7. Mossy fiber $\rightarrow$ interneuron CI AMPA synapses: frequency-dependent facilitation and modulation by metabotropic glutamate receptors. $A$, Single representative experiment showing the frequency-dependent facilitation of mossy fiber $\rightarrow$ interneuron CI AMPA EPSC amplitude. Protocols identical to that described in Figure 6 were used. Open circles represent control recording conditions; solid circles are EPSC amplitudes in MCPG $(0.5 \mathrm{~mm})$. After a return to the control frequency, the solution was then exchanged for one containing MCPG $(0.5 \mathrm{~mm})$, and the experiment was repeated (solid circles). MCPG enhanced the amplitude of mossy fiber $\rightarrow$ interneuron CI AMPA EPSCs only at frequencies of $2 \mathrm{~Hz}$ and above. Traces above the dot plots show averaged EPSCs from four representative frequencies. The EPSC amplitude in the control (dotted traces) is superimposed on the 0.1 and 4 $\mathrm{Hz}$ data to illustrate the frequency-dependent enhancement of EPSCs by MCPG. B, Summary histogram from six experiments showing the mean EPSC facilitation (data normalized to 0.05 $\mathrm{Hz}$ data). Note that the maximum facilitation at $4 \mathrm{~Hz}$ is less pronounced than that observed at mossy fiber $\rightarrow$ pyramidal cell synapses $(350.6 \pm$ $94.3 \%$ of control vs $1049 \pm 260 \%$, respectively; see Fig. 6). MCPG significantly enhanced EPSC amplitude in all experiments only at $2 \mathrm{~Hz}$ and above. $C$, Plot of data from all experiments at 0.1 and $4 \mathrm{~Hz}$ in control and MCPG to illustrate that despite the wide range of frequency-dependent facilitation across all experiments MCPG significantly enhanced transmission only at high and not low frequencies in any experiment.

\section{Interneuron- $\mathrm{Cl}-\mathrm{AMPA}$ Synapse}

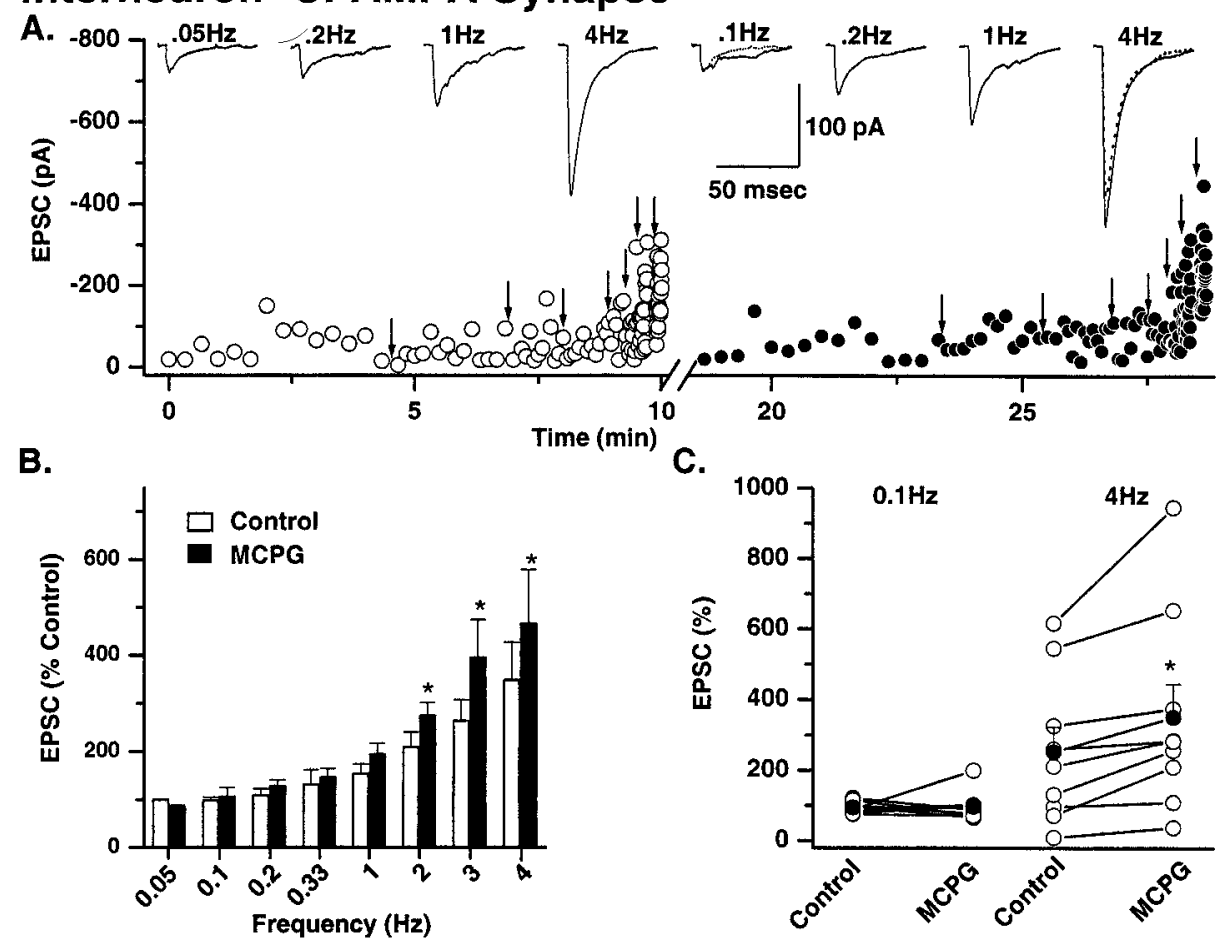

shown, respectively). The facilitation observed at $4 \mathrm{~Hz}$ was also significantly less than that seen at pyramidal neuron synapses [mean facilitation at $4 \mathrm{~Hz}$ was $348 \pm 78.4 \%(n=6)$ and $442.9 \pm$ $104.4 \%(n=8)$ at CI and CP AMPA synapses, respectively; Fig. 7]. These data demonstrate that the dynamic range of mossy fiber synapses is narrower at either synapse type onto interneurons.

In four cells, mossy fiber $\rightarrow$ interneuron synapses actually demonstrated frequency-dependent depression. At frequencies $>1 \mathrm{~Hz}$, transmission fell off rapidly until at $4 \mathrm{~Hz}$ EPSC amplitudes were
$59.8 \pm 25.9 \%(n=3)$ of control at CI AMPA synapses and $66 \%$ of control at a single CP AMPA synapse (data not shown).

\section{Regulation of mossy fiber transmission by presynaptic mGluRs}

When transmitter release is enhanced from mossy fiber $\rightarrow$ pyramidal neuron terminals (e.g., by frequency-dependent facilitation), the concentration of glutamate increases, and its clearance is delayed. This allows glutamate to diffuse away from the synapse and acti- 
vate presynaptic inhibitory metabotropic glutamate receptors, which then rapidly inhibit transmitter release (Scanziani et al., 1997). At low frequencies of transmission the concentration of glutamate released is low enough that presynaptic mGluRs are not activated. We wanted to determine whether a similar phenomenon exists at both types of mossy fiber $\rightarrow$ interneuron synapses.

At all three synapses, in the presence of the broad-spectrum mGluR antagonist $(+) \alpha$-methyl-4-carboxyphenylglycine (MCPG; $0.5 \mathrm{~mm})$, mossy fiber transmission was significantly enhanced at frequencies upward of $1 \mathrm{~Hz}$ compared with control (Figs. 6, 7). The greatest enhancement of facilitation was observed at mossy fiber $\rightarrow$ pyramidal neuron synapses and interneuron CI AMPA synapses. At mossy fiber $\rightarrow$ pyramidal neuron synapses the mean facilitation at $4 \mathrm{~Hz}=1403 \pm 379 \%$ in $\mathrm{MCPG}$ versus $1049 \pm 260 \%$ in control (mean facilitation $=33 \%$ over control; $n=8 ; p=0.03$; Fig. 6). In both types of interneuron synapse enhancement of facilitation by MCPG was only significant at frequencies of $2 \mathrm{~Hz}$ and above (Fig. 7). At interneuron CI AMPA synapses the mean facilitation at $4 \mathrm{~Hz}$ was $350.6 \pm 94.3 \%$ in MCPG compared with $252.5 \pm 70.3 \%$ in control ( $38 \%$ over control; $n=9 ; p=0.017$; Fig. 7). At CP AMPA synapses the mean facilitation at $4 \mathrm{~Hz}$ was $440 \pm$ $103.4 \%$ in $\mathrm{MCPG}$ versus $405.2 \pm 100.8 \%$ in control $(8 \%$ over control; $n=10 ; p=0.0001$; data not shown). It is worth noting that although the degree of facilitation at CP AMPA synapses in the presence of MCPG was significantly enhanced from control, the percent change in facilitation in the presence of MCPG was significantly lower than that seen at both types of CI AMPA synapse.

\section{iLTD occurs only at mossy fiber $\rightarrow$ CP AMPA synapses}

In a previous study, we demonstrated that high-frequency stimulation of mossy fibers induced a target-specific form of long-lasting plasticity at pyramidal versus interneuron synapses (Maccaferri et al., 1998). In response to $100 \mathrm{~Hz}$ stimuli, mossy fiber-pyramidal neurons demonstrated an NMDA-independent form of LTP, whereas interneuron synapses showed either a novel form of NMDA-independent long-term depression [termed "iLTD” by McMahon and Kauer (1997)] or no long-term plasticity [see Maccaferri et al. (1998), their Fig. 1]. Although this iLTD was observed in $\sim 50 \%$ of experiments, at the time we were unaware of the calciumpermeable nature of many mossy fiber AMPA synapses on stratum lucidum interneurons. Therefore we revisited this set of experiments to determine whether iLTD was exclusively associated with one class of interneuron AMPA synapse.

Mossy fiber EPSCs on pyramidal cells and interneurons were evoked at $0.2-0.33 \mathrm{~Hz}$ for a control period of $5-10 \mathrm{~min}$ in the presence of $100 \mu \mathrm{M}$ D,L-APV. A high-frequency induction protocol, comprising a $100 \mathrm{~Hz}$ train of stimuli, $1 \mathrm{sec}$ in duration, repeated three times at $10 \mathrm{sec}$ intervals [this corresponds to the long high-frequency stimulation (L-HFS) used by Yeckel et al. (1999)], was delivered to the mossy fibers. NMDA receptors were blocked (100 $\mu \mathrm{M}$ D,L-APV) throughout all experiments. L-HFS stimulation of mossy fibers evoked LTP at pyramidal cell synapses; EPSCs were increased by $172 \pm 8.9 \%(n=8)$ after the induction protocol (Fig. $8 A$ ). The same induction protocol applied to mossy fiber $\rightarrow$ interneuron synapses resulted in no change in the amplitude or iLTD (Maccaferri et al., 1998). In all cases, iLTD (mean EPSC amplitude measured at $15 \mathrm{~min}$ after induction protocol $=41.6 \pm 7.2 \%$ of control; $n=6$ ) was observed at synapses subsequently identified as containing calcium-permeable AMPA receptors (mean EPSC amplitude in PhTx $=35.4 \pm 7.6 \%$ of control; $n=6$; Fig. $8 C$ ). In contrast, the amplitude of all mossy fiber $\rightarrow$ interneuron CI synapses showed neither LTP or iLTD $(98.9 \pm 13.0 \%$ of control; $n=6)$ nor block by PhTx $(94.7 \pm 5.5 \%$ of control) (Fig. $8 B$ ). These data demonstrate that a common induction protocol differentially affects the long-term efficacy of transmission at three types of mossy fiber synapse.

\section{Long-term changes in synaptic transmission alter short-term plasticity}

The observation that high-frequency stimulation results in differential plasticity at the three types of mossy fiber $\rightarrow$ CA3 synapses

\section{A. CA3 Pyramidal Neuron}

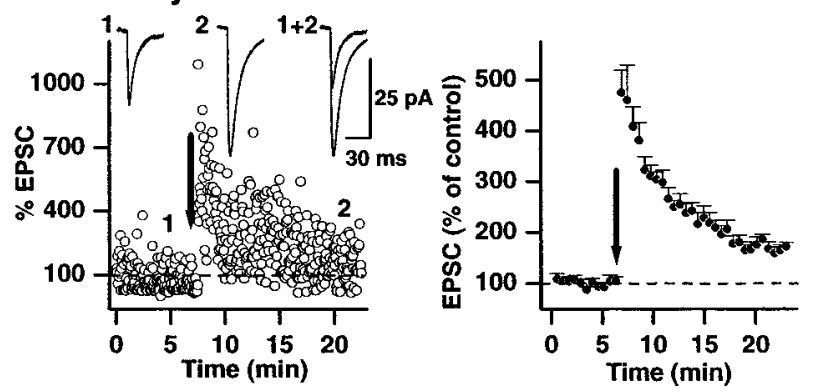

B. Interneuron

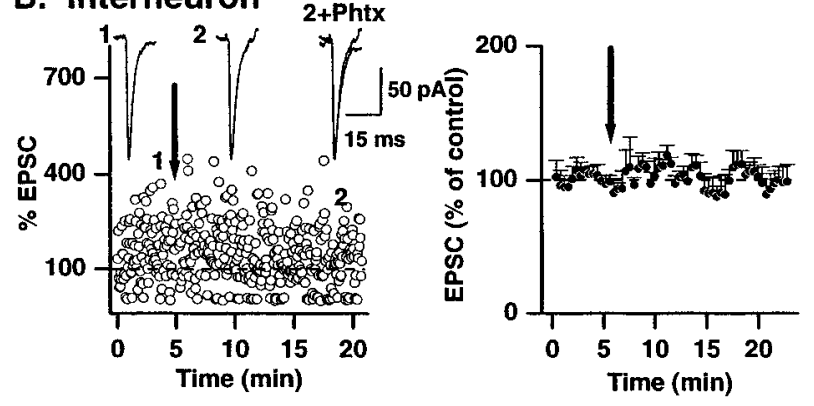

C. Interneuron

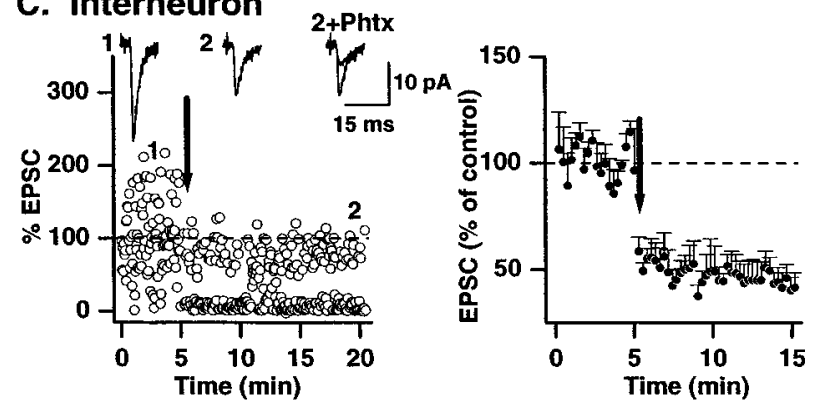

Figure 8. Differential mechanisms of long-term plasticity of synaptic currents at three different mossy fiber synapses. Left, Representative single experiments show that a high-frequency stimulus paradigm $(100 \mathrm{~Hz} ; 1 \mathrm{sec}$; 3 times at $10 \mathrm{sec}$ intervals; indicated by arrow) delivered to mossy fibers differentially affects transmission at all three synapse types. LTP was observed in response to high-frequency stimulation at mossy fiber $\rightarrow$ pyramidal neuron synapses $(A)$ (control stimuli delivered at 0.33 $\mathrm{Hz}$ ), whereas no change or iLTD of the EPSC amplitude was observed at interneuron CI AMPA synapses $(B)$ or CP AMPA synapses $(C)$, respectively (control stimuli delivered at $0.2 \mathrm{~Hz}$ ). Traces above the dot plots show averaged EPSCs (10-20 traces) before (1) and after (2) high-frequency stimulation. Right-most traces in $A$ show Traces 1 and 2 superimposed. In $B, C$, Trace 2 is superimposed on the averaged EPSC amplitude in the presence of PhTx (data points not included in the dot plot for clarity). Right, The mean data from all experiments are shown $(n=8$ pyramidal cells; $n=$ 7 interneuron CI AMPA synapses; $n=6$ interneuron CP AMPA synapses).

prompted us to investigate how these long-term changes in synaptic transmission influence short-term synaptic plasticity. Work on neocortical synapses has suggested that LTP may cause a "redistribution of synaptic strength" in which synaptic responses to the first stimulus in a train are potentiated with later responses depressed (Markram and Tsodyks, 1996). However, this redistribution of synaptic strength was found not to occur at either Schaffer collateral $\rightarrow$ CA1 pyramidal neuron synapses or CA3 $\rightarrow$ CA3 synapses, which show a preservation of the fidelity of postsynaptic responses after induction of NMDA-dependent LTP (Selig et al., 1999). Induction of LTP at mossy fiber $\rightarrow$ pyramidal cell synapses reduces paired-pulse facilitation in response to two closely timed stimuli (Zalutsky and Nicoll, 1990), consistent with a presynaptic locus of expression of mossy fiber-pyramidal neuron LTP. However how this synapse and mossy fiber synapses onto interneurons respond to trains of stimuli (i.e., short-term plasticity) before and after induction of long-lasting plasticity has not been tested. 
To investigate the impact of long-lasting changes in synaptic efficacy on short-term plasticity, a protocol identical to that shown in Figure 8 was used to induce long-term changes in transmission. In addition, we briefly interrupted the slow-frequency stimulation and applied five pulses at $20 \mathrm{~Hz}$ (10 times; at $30 \mathrm{sec}$ intervals; similar to that shown in Fig. 3) before and after the tetanic stimuli. The 10 trains of EPSCs were averaged, and the ratio of the fifth and first EPSC amplitude in the train was measured to evaluate the degree of short-term depression or facilitation before and after induction of long-term plasticity. As described above, highfrequency stimulation evoked LTP, iLTD, and no change in EPSC amplitude at mossy fiber $\rightarrow$ pyramidal cell synapses, $\rightarrow$ interneuron CP AMPA synapses, and $\rightarrow$ CI AMPA synapses, respectively.

In the control period, mossy fiber $\rightarrow$ pyramidal neuron EPSCs were always facilitating in response to the $20 \mathrm{~Hz}$ train (mean facilitation $=516.6 \pm 87.1 \% ; n=9$; Figs. 3, 9). After the induction of LTP, the degree of facilitation was reduced (mean $\mathrm{EPSC}_{5}$ / $\mathrm{EPSC}_{1}$ ratio $\left.=288.9 \pm 56.6 \% ; p=0.0014\right)$. In two cells, facilitation was converted to depression after LTP induction at mossy fiber $\rightarrow$ pyramidal neuron synapses (Fig. 9A, right).

Interneuron CI AMPA synapses showed no change in their response to the $20 \mathrm{~Hz}$ stimulus train after L-HFS (mean $\mathrm{EPSC}_{5}$ / EPSC $_{1}$ ratio $=138.9 \pm 38.5 \%$ before and $137.8 \pm 45.6 \%$ after L-HFS; $n=6 ; p=0.9$ ) as would be expected from synapses that express no form of synaptic plasticity (Fig. 9B). In contrast, shortterm plasticity of interneuron CP AMPA synapses of interneurons was significantly altered after induction of iLTD. In all cells there was an increase in the $\mathrm{EPSC}_{5} / \mathrm{EPSC}_{1}$ ratio. During the control period the response to the $20 \mathrm{~Hz}$ stimuli was either facilitation or depression (mean $\mathrm{EPSC}_{5} / \mathrm{EPSC}_{1}$ ratio $=80.8 \pm 25 \% ; n=6 ; p=$ 0.001 ), but in every case the mean $\mathrm{EPSC}_{5} / \mathrm{EPSC}_{1}$ ratio was significantly increased after the establishment of LTD (mean EPSC $_{5} /$ $\mathrm{EPSC}_{1}$ ratio $=145.7 \pm 25.2 \%$; Fig. $9 \mathrm{C}$ ). These data demonstrate that short-term plasticity in response to brief high-frequency trains of stimuli is determined in part by the long-term plastic state of each mossy fiber synapse.

\section{DISCUSSION}

In a landmark study, Acsady et al. (1998) demonstrated that unlike any other cortical axon, granule cell mossy fibers innervated their target GABAergic interneurons and pyramidal neurons via morphologically distinct presynaptic terminals. A single granule cell axon gives rise to $\sim 15$ large mossy boutons that each contain 20-40 release sites (Chicurel and Harris, 1992; Acsady et al., 1998), with each large mossy bouton contacting a single principal neuron. In contrast, $\sim 50$ small en passant and filopodial terminals established only a single release site onto target GABAergic inhibitory interneurons within the CA3 subfield. These unique features of mossy fiber synapses indicated that granule cells innervate substantially larger numbers of inhibitory interneurons than do pyramidal cells, such that, on average, granule cells contact GABAergic targets approximately five times more frequently than do principal cells. This study suggested that GABAergic cells are the major postsynaptic target of mossy fibers and that these anatomical specializations may endow mossy fiber synapses with unique properties.

In the present study we have extended our previous observations (Maccaferri et al., 1998; Toth and McBain, 1998), showing functional specialization of mossy fiber transmission onto inhibitory interneuron versus pyramidal neuron postsynaptic targets. Here we show that not only do mossy fibers target synapses of distinct AMPA receptor composition on principal and inhibitory interneurons but that regulation of transmission is primarily independent at each synapse type.

Mossy fibers innervated their stratum lucidum inhibitory interneuron targets via synapses comprised of either calcium-permeable or calcium-impermeable AMPA receptors. In contrast, transmission onto principal cells was made exclusively via calciumimpermeable AMPA receptor-containing synapses. The presence of two types of mossy fiber $\rightarrow$ interneuron synapse is somewhat

\section{A. CA3 Pyramidal Neuron}

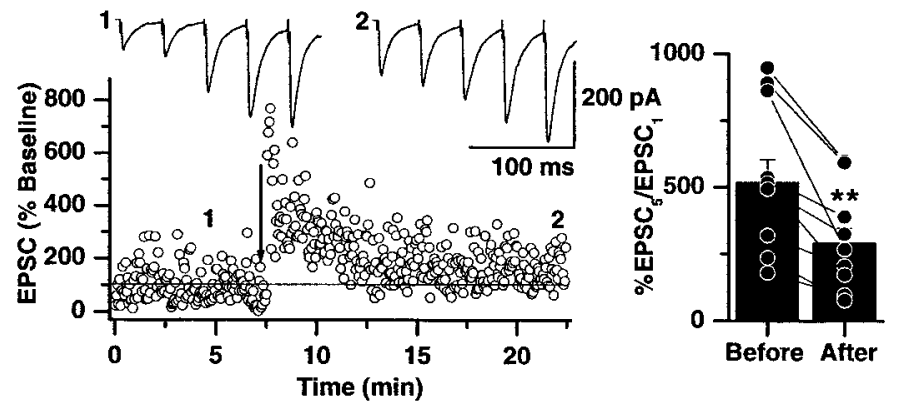

\section{B. Interneuron}

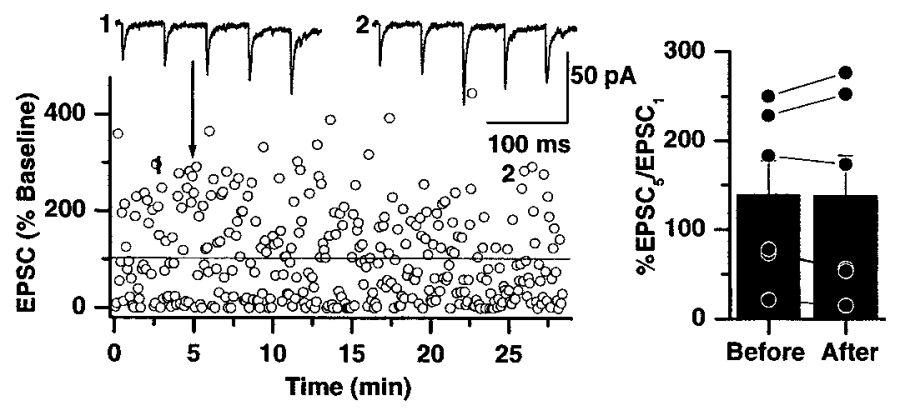

C. Interneuron

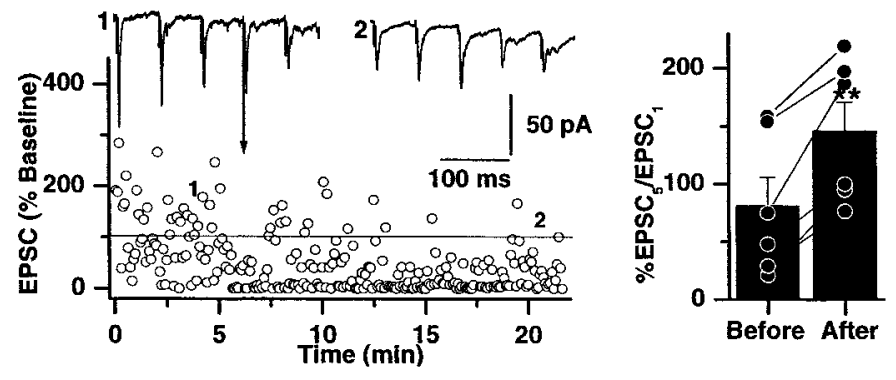

Figure 9. Long-term modification of synaptic efficacy alters short-term plasticity. Single representative experiments recorded from mossy fiber $\rightarrow$ pyramidal cell synapses $(A), \rightarrow$ interneuron CI AMPA synapses $(B)$, and $\rightarrow$ CP AMPA synapses $(C)$ are shown on the left. Sixty EPSCs were evoked at $0.33 \mathrm{~Hz}$ during the control period. The low-frequency stimulation was then briefly interrupted (1), and a train of five stimuli at $20 \mathrm{~Hz}$ (repeated 10 times at $30 \mathrm{sec}$ intervals) was delivered. The averaged response to the 10 trains is shown above the dot plots. A high-frequency stimulus was then applied $(100 \mathrm{~Hz} ; 1 \mathrm{sec} ; 3$ times at $10 \mathrm{sec}$ intervals; indicated by arrow) to induce LTP at mossy fiber $\rightarrow$ pyramidal cell synapses, no change in synaptic plasticity at interneuron CI AMPA synapses, or iLTD at interneuron CP AMPA synapses. Low-frequency stimulation was resumed, and after a period of $10-15 \mathrm{~min}$ the $20 \mathrm{~Hz}$ train was repeated (indicated by 2) to determine the impact of long-term changes in synaptic efficacy on short-term plasticity. The impact of long-term plasticity was determined by comparing the ratio of $\mathrm{EPSC}_{5} / \mathrm{EPSC}_{1}$ during the $20 \mathrm{~Hz}$ train. $A$, The ratio of $\mathrm{EPSC}_{5} / \mathrm{EPSC}_{1}$ was significantly reduced at all mossy fiber $\rightarrow$ pyramidal cell synapses after the induction of LTP. Plots on the right illustrate the $\mathrm{EPSC}_{5} / \mathrm{EPSC}_{1}$ data from all experiments $(n=9)$. Individual experiments are represented by connected dots. The averaged change in EPSC $_{5} /$ EPSC $_{1}$ is shown by the histogram. $B$, As expected, the lack of long-term plasticity at interneuron CI AMPA synapses was without effect on short-term plasticity. The plot on the right indicates the $\mathrm{EPSC}_{5} / \mathrm{EPSC}_{1}$ ratio from all mossy fiber $\rightarrow$ CI AMPA synapses $(n=6)$. No change in the mean $\mathrm{EPSC}_{5} / \mathrm{EPSC}_{1}$ was observed after high-frequency stimulation. $C$, In contrast, the ratio of $\mathrm{EPSC}_{5} / \mathrm{EPSC}_{1}$ was increased after induction of iLTD. In the single experiment shown on the left the mossy fiber $\rightarrow$ CP AMPA synapse is initially depressing (averaged traces evoked by $20 \mathrm{~Hz}$ stimulation shown above the dot plot). After induction of iLTD the $20 \mathrm{~Hz}$ train EPSCs are now facilitating, and the $\mathrm{EPSC}_{5} / \mathrm{EPSC}_{1}$ is greatly increased. In all experiments (indicated on right), regardless of whether the synapse is initially depressing ( $\mathrm{EPSC}_{5} / \mathrm{EPSC}_{1}<100 \%$ ) or facilitating (EPSC ${ }_{5} / \mathrm{EPSC}_{1}>$ $100 \%$ ), the $\mathrm{EPSC}_{5} / \mathrm{EPSC}_{1}$ ratio was significantly greater (indicated by $* *$ ) after the induction of iLTD. 
surprising, and at this time it is unclear what mechanisms exist to determine the composition of AMPA receptors at mossy fiber synapses onto inhibitory interneurons. Although the GABAergic neurons of the stratum lucidum are a heterogeneous population (Freund and Buzsaki, 1996), post hoc examination of cell morphology (see also Toth and McBain, 1998) has revealed few clues as to what cell population(s) or synapse type (filopodial or en passant) is associated with CP or CI AMPA receptors. It is also unclear whether a single interneuron possesses both mossy fiber synapse types or whether one form represents a developmental stage in the mossy fiber synapse maturation. Future studies will address these possibilities.

The kinetics of mossy fiber $\rightarrow$ interneuron transmission was significantly more rapid than that of the transmission onto pyramidal cells. The mean $10-90 \%$ rise time of EPSCs at both types of interneuron synapse was in the submillisecond range, and the time constant for decay was between 1 and $4 \mathrm{msec}$, whereas the $\tau_{\text {decay }}$ of principal cell EPSCs was $\sim 9.0 \mathrm{msec}$. These data are remarkably similar to two previous studies of transmission at mossy fiber $\rightarrow$ CA3 pyramidal cells or $\rightarrow$ dentate gyrus basket cell interneurons (Jonas et al., 1993; Geiger et al., 1997). The more rapid transmission at interneuron synapses in the study of Geiger et al. (1997) was suggested to arise from a combination of the precise timing of glutamate release from the presynaptic terminal and the postsynaptic AMPA receptor subunit composition. In contrast, the large number of release sites at a single mossy fiber bouton onto CA3 pyramidal neurons and the asynchrony of transmitter release from these sites likely contribute to the comparatively prolonged time course of transmission at these synapses (for further discussion, see Henze et al., 2000).

A hallmark of mossy fiber $\rightarrow$ pyramidal neuron transmission is the marked facilitation of EPSCs in response to paired pulse or brief trains of stimuli (Salin et al., 1996; Scanziani et al., 1997; Henze et al., 2000). Here we show that facilitation in response to brief trains of stimuli is significantly less $(\sim 50 \%)$ at both types of inhibitory interneuron synapse than at pyramidal cell synapses. Moreover $\sim 50 \%$ of both synapse types demonstrated short-term depression in response to high-frequency stimulation. Facilitation or depression of transmission at mossy fiber $\rightarrow$ interneuron synapses was primarily determined by the initial release probability of presynaptic transmitter release, with facilitation being most frequently observed when release probability was low (i.e., when $\left[\mathrm{Ca}^{2+}\right]_{\mathrm{o}}$ was reduced). Additional factors, such as the calcium-buffering capabilities, the geometry of the presynaptic terminal, the number of release sites, and the size of the readily releasable pool also may contribute to the degree of facilitation or depression observed at each synapse type.

The degree of frequency-dependent facilitation was also greater at pyramidal neuron synapses, the dynamic range of transmission at mossy fiber $\rightarrow$ pyramidal neuron synapses being approximately three to four times that of both forms of interneuron synapse. Interestingly, despite the lower dynamic range of transmission and differential synapse geometry at interneuron synapses, activation of presynaptic mGluRs reduced transmission in a frequencydependent manner at all three synapses (Scanziani et al., 1997). In CA3 stratum lucidum, mGluR2 immunoreactivity is highest on axon bundles and on large mossy fiber terminals and not on the smaller filopodial terminals (Shigemoto et al., 1997). This distribution pattern suggests that regulation of transmission at all three synapses may be primarily determined by activation of presynaptic mGluRs by glutamate released primarily from synapses proximal to the large mossy fiber terminals. Interestingly, MCPG increased facilitation by $\sim 35 \%$ at both pyramidal neuron and interneuron CI AMPA synapses, whereas transmission at CP AMPA synapses increased by only $\sim 10 \%$. This may suggest that CI synapses are preferentially associated with filopodial extensions, which arise from the large mossy boutons, whereas CP synapses may be made by en passant synapses. Such a hypothesis will be tested in future studies.

Despite their higher calcium permeability, it has been unclear what physiological role GluR2-lacking, calcium-permeable AMPA receptors impart to the numerous synapses at which they are expressed. A study by Rozov and Burnashev (1999), however, demonstrated a unique form of short-term synaptic plasticity that results from unblock of intracellular polyamines from the postsynaptic CP AMPA receptor ion channel. The mechanism of unblock is both voltage and use dependent (Bowie et al., 1998; Rozov et al., 1998; Rozov and Burnashev, 1999), suggesting that short-term facilitation would be greatest at more depolarized potentials. Here we show that such a mechanism also exists at interneuron $\mathrm{CP}$ AMPA synapses and provides an additional mechanism for the short-term enhancement of synaptic gain located postsynaptically. The degree of facilitation observed at $-20 \mathrm{mV}$ was almost double that observed at $-80 \mathrm{mV}$. Such a mechanism would act to boost subthreshold EPSCs to elicit action potential firing despite the reduced driving force at depolarized potentials.

A novel form of long-term plasticity was also identified at interneuron CP AMPA synapses. In response to stimuli that induced an NMDA-independent form of long-term potentiation at mossy fiber $\rightarrow$ pyramidal cell synapses, interneuron CP AMPA synapses underwent long-term depression. This long-term depression was qualitatively similar to both the iLTD first described by McMahon and Kauer (1997) at other interneuron excitatory synapses and that shown to be peculiar to CP AMPA receptor synapses on CA3 radiatum interneurons (Laezza et al., 1999). Whether these three types of iLTD share common mechanisms remains to be tested. In the present study an identical pattern of stimuli delivered to mossy fiber axons resulted in opposing long-term changes in synaptic efficacy at principal versus interneuron synapses. Such differential changes in synaptic efficacy will likely act to shift the balance of excitation/inhibition in favor of excitation in the mossy fiber $\rightarrow$ CA3 system by reducing the excitatory drive of mossy fiber $\rightarrow$ interneuron CP AMPA synapses at low-stimulation frequencies. It is worth noting that interneuron synapses comprised of calcium-impermeable AMPA receptors underwent no form of long-term change in synaptic efficacy in response to high-frequency stimulation (Maccaferri et al., 1998). This suggests that similar to studies of NMDA-dependent forms of LTP in interneurons (for review, see McBain et al., 1999), these synapses lack the appropriate machinery for induction of long-lasting changes in synaptic efficacy.

In agreement with a presynaptic locus of expression for mossy fiber long-term plasticity (Zalutsky and Nicoll, 1990; Yeckel et al., 1999), we found that after induction of long-term plasticity the degree of facilitation and/or depression in response to short trains of stimuli was altered in a manner consistent with a change in the initial release probability of presynaptic transmitter release. Induction of LTP at mossy fiber $\rightarrow$ pyramidal neuron synapses reduced the degree of facilitation in response to a brief high-frequency train. Conversely induction of iLTD at interneuron CP AMPA synapses increased the degree of facilitation or reduced the degree of depression observed in response to an identical train of stimuli. These data suggest that the dynamic range of high-frequency transmission at interneuron synapses would be increased while the degree of short-term facilitation at pyramidal neuron synapses would be decreased after induction of long-term plasticity. Such mechanisms will act to increase the computational prowess of the mossy fiber system.

In conclusion, here we have shown that transmission between mossy fibers and their principal and interneuron targets is differentially regulated at each of the three synapse types. The large differences in the dynamic range and the differential short- and long-term plastic properties of these three synapses suggest that each synapse type can form a functional unit whose transmission can be regulated somewhat independently by both presynaptic and postsynaptic mechanisms.

\section{REFERENCES}

Acsady L, Kamondi A, Sik A, Freund T, Buzsaki G (1998) GABAergic cells are the major postsynaptic targets of mossy fibers in the rat hippocampus. J Neurosci 18:3386-3403. 
Amaral DG (1979) Synaptic extensions from the mossy fibers of the fascia dentata. Anat Embryol (Berl) 155:241-251.

Amaral DG, Dent JA (1981) Development of the mossy fibers of the dentate gyrus. I. A light and electron microscopic study of the mossy fibers and their expansions. J Comp Neurol 195:51-86.

Amaral DG, Ishizuka N, Claiborne B (1990) Neurons, numbers and the hippocampal network. Prog Brain Res 83:1-11.

Bahring R, Bowie D, Benveniste M, Mayer ML (1997) Permeation and block of rat GluR6 glutamate receptor channels by internal and external polyamines. J Physiol (Lond) 502:575-589.

Blackstad TW, Kjaerheim A (1961) Special axo-dendritic synapses in the hippocampal cortex: electron and light microscopic studies on the layer of mossy fibers. J Comp Neurol 117:113-159.

Blaschke M, Keller BU, Rivosecchi R, Hollmann M, Heinemann S, Konnerth A (1993) A single amino acid determines the subunit-specific spider toxin block of alpha-amino-3-hydroxy-5-methylisoxazole-4-propionate/kainate receptor channels. Proc Natl Acad Sci USA 90:6528-6532

Bowie D, Mayer ML (1995) Inward rectification of both AMPA and kainate subtype glutamate receptors generated by polyamine-mediated ion channel block. Neuron 15:453-462.

Bowie D, Lange GD, Mayer ML (1998) Activity-dependent modulation of glutamate receptors by polyamines. J Neurosci 18:8175-8185.

Brackley PT, Bell DR, Choi SK, Nakanishi K, Usherwood PN (1993) Selective antagonism of native and cloned kainate and NMDA receptors by polyamine-containing toxins. J Pharmacol Exp Ther 266:1573-1580.

Chicurel ME, Harris KM (1992) Three-dimensional analysis of the structure and composition of CA3 branched dendritic spines and their synaptic relationships with mossy fiber boutons in the rat hippocampus. J Comp Neurol 325:169-182.

Claiborne BJ, Amaral DG, Cowan WM (1986) A light and electron microscopic analysis of the mossy fibers of the rat dentate gyrus. J Comp Neurol 246:435-458.

Creager R, Dunwiddie T, Lynch G (1980) Paired-pulse and frequency facilitation in the CA1 region of the in vitro rat hippocampus. J Physiol (Lond) 299:409-424.

Debanne D, Guerineau NC, Gahwiler BH, Thompson SM (1996) Pairedpulse facilitation and depression at unitary synapses in rat hippocampus: quantal fluctuation affects subsequent release. J Physiol (Lond) 491:163-176.

delCastillo J, Katz B (1954) Quantal components of the end-plate potential. J Physiol (Lond) 124:560-573.

Freund TF, Buzsaki G (1996) Interneurons of the hippocampus. Hippocampus 6:347-470.

Geiger JRP, Lubke J, Roth A, Frotscher M, Jonas P (1997) Submillisecond AMPA receptor-mediated signaling at a principal neuroninterneuron synapse. Neuron 18:1009-1023.

Gulyas AI, Miles R, Sik A, Toth K, Tamamki N, Freund TF (1993) Hippocampal pyramidal cells excite inhibitory interneurons through a single release site. Nature 366:683-687.

Henze DA, Urban NN, Barrionuevo G (2000) The multifarious hippocampal mossy fiber pathway: a review. Neuroscience 98:407-427.

Herlitze S, Raditsch M, Ruppersberg JP, Jahn W, Monyer H, Schoepfer R, Witzemann V (1993) Argiotoxin detects molecular differences in AMPA receptor channels. Neuron 10:1131-1140.

Jonas P, Burnashev N (1995) Molecular mechanisms controlling calcium entry through AMPA-type glutamate receptor channels. Neuron 15:987-990.

Jonas P, Major G, Sakmann B (1993) Quantal components of unitary EPSCs at the mossy fibre synapse on CA3 pyramidal cells of rat hippocampus. J Physiol (Lond) 472:615-663.

Kamboj SK, Swanson GT, Cull-Candy SG (1995) Intracellular spermine confers rectification on rat calcium-permeable AMPA and kainate receptors. J Physiol (Lond) 486:297-303.

Kamiya H, Shinozaki H, Yamamoto C (1996) Activation of metabotropic glutamate receptor type $2 / 3$ suppresses transmission at rat hippocampal mossy fibre synapses. J Physiol (Lond) 493:447-455.

Kapur A, Yeckel MF, Gray R, Johnston D (1998) L-type calcium channels are required for one form of hippocampal mossy fiber LTP. J Neurophysiol 79:2181-2190.

Koh DS, Burnashev N, Jonas P (1995) Block of native Ca(2+)-permeable AMPA receptors in rat brain by intracellular polyamines generates double rectification. J Physiol (Lond) 486:305-312.

Laezza F, Doherty JJ, Dingledine R (1999) Long-term depression in hippocampal interneurons: joint requirement for pre- and postsynaptic events. Science 285:1411-1414.
Maccaferri G, McBain CJ (1995) Passive propagation of LTD to stratum oriens-alveus inhibitory neurons modulates the temporoammonic input to the hippocampal CA1 region. Neuron 15:137-145.

Maccaferri G, Toth K, McBain CJ (1998) Target-specific expression of presynaptic mossy fiber plasticity. Science 279:1368-1370.

Manabe T, Wyllie DJ, Perkel DJ, Nicoll RA (1993) Modulation of synaptic transmission and long-term potentiation: effects on paired pulse facilitation and EPSC variance in the CA1 region of the hippocampus. J Neurophysiol 70:1451-1459.

Manzoni OJ, Castillo PE, Nicoll RA (1995) Pharmacology of metabotropic glutamate receptors at the mossy fiber synapses of the guinea pig hippocampus. Neuropharmacology 34:965-971.

Markram H, Tsodyks M (1996) Redistribution of synaptic efficacy between neocortical pyramidal neurons. Nature 382:807-810.

Markram H, Wang Y, Tsodyks M (1998) Differential signaling via the same axon of neocortical pyramidal neurons. Proc Natl Acad Sci USA 95:5323-5328.

McBain CJ (1998) A short-term mechanism of plasticity for interneurones? J Physiol (Lond) 511:331.

McBain CJ, Freund TF, Mody I (1999) Glutamatergic synapses onto hippocampal interneurons: precision timing without lasting plasticity. Trends Neurosci 22:228-235.

McMahon L, Kauer JA (1997) Hippocampal interneurons express a novel form of synaptic plasticity. Neuron 18:295-305.

Ramon y Cajal S (1911) Histologie de systeme nerveux de l'homme et des vertebras tome II. Paris: Maloine.

Reyes A, Sakmann B (1999) Developmental switch in the short-term modification of unitary EPSPs evoked in layer $2 / 3$ and layer 5 pyramidal neurons of rat neocortex. J Neurosci 19:3827-3835.

Reyes A, Lujan R, Rozov A, Burnashev N, Somogyi P, Sakmann B (1998) Target-cell-specific facilitation and depression in neocortical circuits. Nat Neurosci 1:279-285.

Rozov A, Burnashev N (1999) Polyamine-dependent facilitation of postsynaptic AMPA receptors counteracts paired-pulse depression. Nature 401:594-598.

Rozov A, Zilberter Y, Wollmuth LP, Burnashev N (1998) Facilitation of currents through rat $\mathrm{Ca}^{2+}$-permeable AMPA receptor channels by activity-dependent relief from polyamine block. J Physiol (Lond) 511:361-377.

Salin PA, Scanziani M, Malenka RC, Nicoll RA (1996) Distinct shortterm plasticity at two excitatory synapses in the hippocampus. Proc Natl Acad Sci USA 93:13304-13309.

Scanziani M, Salin PA, Vogt KE, Malenka RC, Nicoll RA (1997) Usedependent increases in glutamate concentration activate presynaptic metabotropic glutamate receptors. Nature 385:630-634.

Scanziani M, Gahwiler BH, Charpak S (1998) Target cell-specific modulation of transmitter release at terminals from a single axon. Proc Natl Acad Sci USA 95:12004-12009.

Selig DK, Nicoll RA, Malenka RC (1999) Hippocampal long-term potentiation preserves the fidelity of postsynaptic responses to presynaptic bursts. J Neurosci 19:1236-1246.

Shigemoto R, Kinoshita A, Wada E, Nomura S, Ohishi H, Takada M, Flor PJ, Neki A, Nakanishi S, Mizuno N (1997) Differential presynaptic localization of metabotropic glutamate receptor subtypes in the rat hippocampus. J Neurosci 17:7503-7522.

Spruston NP, Jonas P, Sakmann B (1995) Dendritic glutamate receptor channels in rat hippocampal CA3 and CA1 pyramidal neurons. J Physiol (Lond) 482:325-352.

Toth K, McBain CJ (1998) Afferent specific innervation of two distinct AMPA receptor subtypes on single hippocampal interneurons. Nat Neurosci 1:572-578.

Toth K, McBain CJ (2000) Target-specific expression of pre- and postsynaptic mechanisms. J Physiol (Lond) 525:41-51.

Washburn MS, Dingledine R (1996) Block of alpha-amino-3-hydroxy-5methyl-4-isoxazolepropionic acid (AMPA) receptors by polyamines and polyamine toxins. J Pharmacol Exp Ther 278:669-678.

Yeckel MF, Kapur A, Johnston D (1999) Multiple forms of LTP in hippocampal CA3 neurons use a common postsynaptic mechanism. Nat Neurosci 2:625-633.

Zalutsky RA, Nicoll RA (1990) Comparison of two forms of long-term potentiation in single hippocampal neurons. Science 248:1619-1624.

Zucker RS (1989) Short-term synaptic plasticity. Annu Rev Neurosci 12:13-31.

Zucker RS (1999) Calcium- and activity-dependent synaptic plasticity. Curr Opin Neurobiol 9:305-313. 